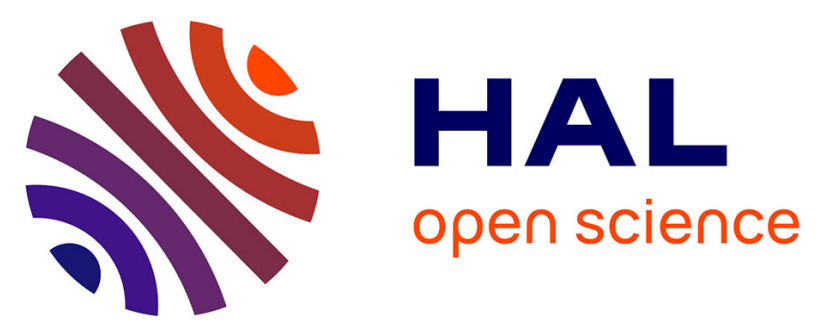

\title{
Prognostic value of new onset atrial fibrillation after transcatheter aortic valve implantation: A FRANCE 2 registry substudy
}

Akira Furuta, Nicolas Lellouche, Gauthier Mouillet, Tarvinder Dhanjal, Martine Gilard, Marc Laskar, Hélène Eltchaninoff, Jean Fajadet, Bernard Lung, Patrick Donzeau-Gouge, et al.

\section{To cite this version:}

Akira Furuta, Nicolas Lellouche, Gauthier Mouillet, Tarvinder Dhanjal, Martine Gilard, et al.. Prognostic value of new onset atrial fibrillation after transcatheter aortic valve implantation: A FRANCE 2 registry substudy. International Journal of Cardiology, 2016, 210, pp.72-79. 10.1016/j.ijcard.2016.02.073 . hal-01274300

\section{HAL Id: hal-01274300 https://hal-univ-rennes1.archives-ouvertes.fr/hal-01274300}

Submitted on 7 Sep 2016

HAL is a multi-disciplinary open access archive for the deposit and dissemination of scientific research documents, whether they are published or not. The documents may come from teaching and research institutions in France or abroad, or from public or private research centers.
L'archive ouverte pluridisciplinaire HAL, est destinée au dépôt et à la diffusion de documents scientifiques de niveau recherche, publiés ou non, émanant des établissements d'enseignement et de recherche français ou étrangers, des laboratoires publics ou privés. 


\section{Prognostic value of new onset atrial fibrillation after transcatheter aortic valve implantation: A FRANCE 2 Registry Substudy}

Akira Furuta MD*\#; Nicolas Lellouche MD*; Gauthier Mouillet MD*; Tarvinder Dhanjal MD*; Martine Gilard MD1; Marc Laskar MD2; Helene Eltchaninoff MD3, Jean Fajadet MD4; Bernard Iung MD5; Patrick Donzeau-Gouge MD6; Pascal Leprince MD7; Alain Leuguerrier MD8; Alain Prat MD9 ; Jean-Luc Dubois-Rande MD* ; Emmanuel Teiger MD*

\# Cardiovascular Center, Ageo Central General Hospital, 1-10-10 Kashiwaza, Ageo, 362-8588 Saitama, Japan.

* Cardiology Department, Hôpital Henri-Mondor, Assistance-Publique-Hôpitaux-de-Paris, 51 Avenue du Maréchal de Lattre de Tassigny 94000 CRETEIL, France

1 Cardiology Department, Centre-Hospitalier-Universitaire de Brest, Hôpital de la CavaleBlanche, boulevard Tanguy Prigent, 29609 Brest.

2 Cardiac Surgery Unit, Centre-Hospitalier-Universitaire de Limoges, 2 avenue Martin Luther king, 87042 Limoges Cedex 
з Cardiology Department, Centre-Hospitalier-Universitaire de Rouen, 1 rue de Germont, Rouen

${ }_{4}$ Cardiology Department, Clinique Pasteur, Centre de recherche cardiologique, 1 rue de la petite vitesse, 31000 Toulouse

5 Cardiology Department, Centre-Hospitalier-Universitaire Xavier Bichat, Université Paris Diderot, 16 rue Henri-Huchard, 75018 Paris

${ }_{6}$ Cardiac Surgery Unit, Institut-Cardiovasculaire Paris-Sud, Massy, France

7 Cardiac Surgery Unit, Centre-Hospitalier-Universitaire Pitié salpêtrière, Université Paris 8 CHU Rennes, Rennes, France, 2 rue Henri le Guilloux, Rennes

9 Cardiac Surgery Unit, Centre-Hospitalier-Universitaire de Lille, 12 rue Jean Jaurès, Lille The all authors are on behalf of FRANCE 2 Registry Investigators.

“Address for correspondence” Akira Furuta,

\# Cardiovascular Center, Ageo Central General Hospital, 1-10-10 Kashiwaza, Ageo, 362-8588 Saitama, Japan. Tel: (+81) $48 \quad 773 \quad 1111$ fax: (+81) $48 \quad 7722205$. E-mail:frtakr@gmail.com 
* Cardiology Department, Hôpital Henri-Mondor, Assistance-Publique-Hôpitaux-de-Paris,

51 Avenue du Maréchal de Lattre de Tassigny 94000 CRETEIL, France

The two first authors equally contributed to this work.

Total word count; 4628

Brief title: Prognostic value of NOAF post-TAVI

\section{Highlights}

- $\quad$ Patients were divided into 2 groups by the presence or absence of NOAF post TAVI.

- $\quad$ No-NOAF was observed in 92.4\%: control group and NOAF in 7.6\%: NOAF group.

- $\quad$ Thirty-day and 1-year mortality were significantly higher in the NOAF group.

- $\quad$ Age, major life-threatening bleeding are the independent predictors of NOAF.

- $\quad$ Trend towards a higher incidence of bleeding was only observed in the TA approach. 


\section{Abstract}

\section{Background}

The development of new onset atrial fibrillation (NOAF) post-transcatheter aortic valve implantation (TAVI) is common and may be associated with an adverse prognosis. This study seeks to identify incidence, predictors, and impact of NOAF post-TAVI.

\section{Methods}

From the multicenter study of the French national transcatheter aortic valve implantation registry, FRANCE 2, a total of 1959 patients with sinus rhythm prior to TAVI were enrolled into this study. The incidence of post-TAVI NOAF, predictors of development of NOAF and impact on 30-day and 1-year-mortality were assessed.

\section{Results}

Of the 1959 TAVI patients (mean-age:82.6 \pm 7.5 years, mean-logistic-EuroSCORE: 21.8 \pm 14.3 ), 149 (7.6\%) developed NOAF with the remaining 1810 (92.4\%) control patients demonstrating no evidence of AF as defined by Valve Academic Research Consortium (VARC). Advanced age, major life-threatening bleeding were independent predictors of NOAF (95\%CI:0.93-0.99;p=0.006, 95\%CI:1.58-4.00;p<0.001，95\%CI:1.09-3.75;p=0.025, 
respectively). A trend towards a higher incidence of major life-threatening bleeding was observed in the patients undergoing TAVI via the transapical(TA)-approach compared with the transfemoral(TF)-approach. Both 30-day and cumulative 1-year-mortality were significantly higher in patients with NOAF compared to patients without NOAF (3.0\% vs. 7.4\%; $=0.005,9.1 \%$ vs. 20.8\%; $<0.001$, respectively). In addition, NOAF was an independent predictor of 30-day and 1-year-mortality (HR:2.16; 95\%CI:1.06-4.41;p=0.033, HR:2.12; 95\%CI:1.42-3.15;p<0.001, respectively).

\section{Conclusion}

Advanced age, major and life-threatening bleeding were independently associated with increased incidence of NOAF, which itself was an independent predictor of 30-day and 1-year-mortality. With regards to the various transcatheter approaches, a trend towards a higher incidence of major life-threatening bleeding was observed only with the TA-approach.

\section{Key words}

aortic stenosis; TAVI; atrial fibrillation 


\section{Introduction}

Within the past few years the number of transcatheter aortic valve implantation (TAVI)

procedures has increased considerably. ${ }^{1}$ Although TAVI yields a significant survival benefit in inoperable patients with aortic stenosis (AS), the mortality rate at 1 -year remains high. ${ }^{2,3}$

The French national TAVI registry, FRANCE 2, demonstrated recently that this procedure is effective in terms of feasibility, safety, short-term haemodynamic and functional improvement. However, a number of TAVI-associated complications have been identified, including the prevalent post-procedural development of new onset atrial fibrillation (NOAF). Indeed, recent published data has suggested that NOAF is associated with an unfavorable clinical outcome post-TAVI. Studies have started to evaluate NOAF after TAVI, which is associated with a higher rate of stroke/systemic embolism and higher mortality and morbidity after TAVI. ${ }^{4,5}$ The aim of our study was to better characterise the incidence, predictors and impact of NOAF on short- and mid-term follow up post-TAVI from the multicenter large-cohort FRANCE 2 registry.

\section{Methods}




\section{1. Study population}

At the beginning of January 2010, a national TAVI coordination and monitoring program was established in France to analyze patient characteristics such as age, logistic EuroScore, and echo-cardiographic data, and clinical outcomes in 33 medical centers in France and 1 center in Monaco, with the capability of performing TAVI using 1 of the following approach: transfemoral (TF), transapical (TA), subclavian, or other techniques such as direct-transaortic or carotid routes. Each multidisciplinary team performing the procedure consisted of an interventional cardiologist, cardiothoracic surgeon, cardiologist, echocardiographer, anesthetist, imaging specialist and geriatrician. The multidisciplinary teams identified patients eligible for TAVI as symptomatic patients with severe AS who were at high risk and ineligible for surgical aortic valve replacement (SAVR) owing to comorbidities. In all centers, each team determined the eligibility for TAVI based on systematic clinical, angiographic, multislice-computed-tomographic, and echocardiographic assessments. The patients were divided into 2 groups according to the absence or presence of NOAF. All the patients provided written informed consent prior to the procedure and 
consented to the anonymous processing of their data. NOAF was diagnosed according to the Valve Academic Research Consortium (VARC) criteria. The Institutional Review Board of the French Ministry of Health approved the registry. Clinical data, patient characteristics, echocardiographic data, procedural variables, length of hospital-stay, and in-hospital and all-cause mortality were prospectively analysed for each group.

\section{2. TAVI Procedure}

The TAVI procedure has previously been described in detail. ${ }^{6}$ Both commercially available valves were used: the balloon-expandable prosthesis known as the Edwards SAPIEN valve (ES; Edwards Lifesciences, Irvine, CA, USA) and the self-expandable prosthesis known as the Medtronic CoreValve Revalving System (CV; Medtronic, Minneapolis, MN, USA). There was no prespecified recommendation with respect to the use of TF, TA, subclavian, or the other approaches. TF-access was obtained percutaneously or after surgical cut-down, and TA-access by anterior-minithoracotomy. Rapid ventricular pacing was used to deploy the ES valve. The TF-access was closed surgically or percutaneously (Prostar XL, Abbott). All patients received aspirin ( $\leq 160 \mathrm{mg}$ daily) and clopidogrel (300 mg loading dose, then 75 
mg daily) before the procedure and aspirin alone after 1-month of dual anti-platelet therapy.

The choice between general and local anaesthesia for TF implantation was at the operators discretion.

\section{3. NOAF definition}

Patients were on continuous electrocardiogram monitoring until hospital discharge, and

NOAF was defined as any episode of AF lasting longer than $30 \mathrm{s.}^{6,7}$ The timing and duration of episodes of NOAF and the requirement for electrical or pharmacological cardioversion were recorded. The duration of NOAF episodes were classified as follows: $<1$ min, 1 min to $1 \mathrm{~h}, 1$ to $12 \mathrm{~h}, 12$ to $24 \mathrm{~h}, 24$ to $48 \mathrm{~h}$, or $>48 \mathrm{~h}$. The management of NOAF was as stated within the latest reviewed guidelines of the American College of Cardiology/American Heart Association. ${ }^{7}$ Anticoagulation was started, unless contraindicated, immediately after the diagnosis of NOAF and continued for at least 1 month. In the case of short episodes $(<12 \mathrm{~h})$ of $\mathrm{AF}$, the potential risks/benefits of anticoagulation were evaluated in each patient, and the decision was made by the responsible physician. In addition beta-blocker therapy was added in patients with AF to 
maintain the heart rate $<80 /$ min at rest or $<110 /$ min during exercise. In patients with an epidural catheter for pain relief post-TA TAVI, anticoagulation was delayed for $24 \mathrm{~h}$ after the removal of the catheter following guidelines of the American Association of Regional Anesthesia and Pain Medicine. ${ }^{8}$ Warfarin was used as the anticoagulant therapy in all cases, with a target international normalized ratio between 2 and 3. Intravenous heparin was administered until therapeutic anticoagulation levels were achieved. If the heart rate during AF was superior than 110 beats per minutes at rest, beta-blocker therapy were started.

\section{4. Study end-points and follow-up}

The primary end-point was death from any cause at 1-year follow-up. Secondary clinical endpoint was cardiovascular death at 1-year follow-up. The definition of cardiovascular death has been described previously. ${ }^{9}$ We recorded all-cause mortality, cardiovascular death and clinical events during follow-up. Procedure success and other procedural complications during TAVI were evaluated according to the VARC criteria. ${ }^{10}$ All adverse events following TAVI were also assessed according to the VARC. The definition of NOAF lacks standardization as it is often defined as detection of AF in patients with no previous known 
AF, but the set-point for minimum episode duration varies. ${ }^{4,11}$ In an effort to standardize different end-points post TAVI, VARC proposed that NOAF should be diagnosed as AF detected during hospitalization and lasting long enough to be recorded on a 12-lead ECG or at least 30 seconds on a rhythm strip. ${ }^{10}$ The post procedural bleeding complications were categorized as life threatening, major, or minor. Stroke and vascular complications (VC) were also categorized as major or minor. Post-procedural aortic and mitral regurgitation were assessed by transthoracic echocardiography at 1, 3, 6, and 12 months post-operatively. Mortality and cardiovascular death was adjudicated by an independent clinical events committee at 30-day and 1-year follow-up for all patients.

\section{5. Data management and statistical analysis}

Data were recorded on a standardized electronic case report form and sent to an on-line network central database (AXONAL, Nanterre, France). Quality control was performed for $10 \%$ of patients in randomly selected centres. All statistical analyses were performed using SPSS software, Version 19 (SPSS Inc., Chicago, IL, USA). Continuous variables were expressed as mean \pm standard deviation or median \pm interquartile range (IQR), depending 
on variable distribution. Categorical data were expressed as percentage of the total. The comparative analyse between the 2 study groups was performed with ANOVA test. For categorical variables a Chi-square test or exact Fischer's test was performed if necessary. Multivariate logistic regression was performed to identify independent predictors of NOAF. The multivariable model was built by selecting variables of clinical interest and/or satisfying the entry criterion of $\mathrm{p}<0.10$ in the univariate analysis. Variables included in the model were carefully selected to avoid overfitting. All selected variables were entered at the same time. Prognostic values of NOAF for 30-day and 1-year outcome in the NOAF group, in comparison with the control group, were assessed using a Cox regression hazard model. A univariate COX regression analysis was performed to obtain the hazard ratio (HR) for 30-day and 1-year mortality. Thereafter, a multivariate analysis was performed using the variables with $\mathrm{p}$-values $<0.10$ in the univariate analysis in order to examine their independent association with 30-day and 1-year mortality. The Kaplan-Meier (KM) method was used to estimate cumulative mortality in the both study groups. Survival differences in each group were compared with the log-rank test. The statistical tests were two-sided and a p-value $<0.05$ was considered to be significant. 


\section{Results}

\section{1. Patient characteristics}

In this multicenter FRANCE 2 registry, TAVI was performed in 3,195 patients, and 1959 patients (61.3\%) with sinus rhythm preceding TAVI were enrolled into this study, and 1,236 patients (38.7\%) presenting prior atrial fibrillation (AF), atrial flutter, pacemaker implantation preceding TAVI were excluded. Among them, 149 (7.6\%) patients had a diagnosis of NOAF following the index procedure. Baseline and procedural characteristics of patients stratified by occurrence of NOAF are shown in Table 1 and Table 2. Age, prevalence of pulmonary hypertension and logistic EuroSCORE were significantly higher in the NOAF group ( $\mathrm{p}=0.001, \mathrm{p}=0.001, \mathrm{p}=0.021$, respectively) compared to the control group. Echocardiographic measurements revealed significant differences in aortic valve area $(0.68 \mathrm{~cm} 2$ vs. $0.62 \mathrm{~cm} 2, \mathrm{p}<0.001)$ and systolic pulmonary arterial pressures (PAP) (43.6 mmHg vs. $47.7 \mathrm{mmHg}, \mathrm{p}=0.002$ ) in control versus NOAF groups respectively. A higher incidence of NOAF was observed in the patients using TA-approach compared to TF 
and subclavian approaches ( $13.5 \%$ vs. $6.0 \%$ vs. $6.4 \%$, respectively, $\mathrm{p}<0.001)$. Age was an independent variable for predicting NOAF (Table 3-1).

\section{2. Post-procedural immediate follow-up and complications}

Post-procedural clinical outcomes of patients stratified by control group versus NOAF group are shown in Table 2. The risk of death from any cause within 30-day was significantly higher in the NOAF group compared to the control group ( $\mathrm{p}=0.005)$. In addition, a significantly higher incidence of major or life-threatening bleeding was observed on the NOAF group compared to the control group ( $\mathrm{p}=0.024)$. A trend toward higher incidence of minor bleeding and need for vascular surgery was also observed on the NOAF group compared to the control group ( $\mathrm{p}=0.078, \mathrm{p}=0.051$, respectively). The duration of stay in the intensive care unit (ICU-stay) and hospitalization post-procedure was longer in the NOAF group compared to the control group (4.72 days vs. 3.65 days, $\mathrm{p}=0.006,12.29$ days vs. 9.67 days, $\mathrm{p}<0.001$, respectively). A trend towards a higher incidence of major and life-threatening bleeding was observed in the patients undergoing a TA-approach. (Table 4) Life-threatening and major bleeding were independent variables predicting NOAF. (Table 


\section{3. Early and medium term follow-up and factors associated with mortality}

\section{3. 1. 30-day mortality}

After the index procedure, median follow-up was 153 days (IQR: 11 to 295 days). Of the 1959 TAVI patients presenting with sinus rhythm at baseline, 65 (3.3\%) died during the postoperative 30 days and 195 (10.0\%) died during the postoperative 1 year follow up. Cumulative 30-day mortality in the control and NOAF-group was $3.0 \%$ and $7.4 \%$, respectively. The KM survival curve for 30-day mortality demonstrated a significant survival difference between the 2 groups $(\mathrm{p}=0.005)$ as shown in Figure 1 . Though a trend toward lower rates of survival was observed in the patient undergoing a TA-approach compared to TF and the other approaches in the control group $(\mathrm{p}=0.085)$, no differences in survival rates due to theses modalities was observed in the NOAF group ( $\mathrm{p}=0.635)$. The association between the post-procedural variables and the 30-day mortality are shown in Table 5. NOAF, major stroke, major VC, major and life-threatening bleeding, new pacemaker implantation, 2 valve implantation, acute kidney injury (AKI) requiring 
hemodialysis, and AR of more than grade $2(\mathrm{AR}>2)$ were associated with increased 30-days mortality in the univariate model. In multivariate analysis, NOAF [HR: 2.16, 95\% confidence interval (CI): 1.06-4.41, $\mathrm{p}=0.033$ ], major stroke [HR: 3.34, 95\%CI: 1.31-8.50, $\mathrm{p}=0.011]$, major and life-threatening bleeding [HR: 2.76, 95\% confidence interval (CI): 1.33-5.70, p=0.006], AKI needing for hemodialysis [HR: 6.28, 95\%CI: 2.59-15.23, $\mathrm{p}<0.001$ ] and AR $>2$ [HR: 1.79, 95\%CI: 1.01-3.17, $\mathrm{p}=0.047$ ] were independently associated with an increased risk of 30-day mortality.

\section{3. 2. 1-year mortality}

Cumulative 1-year mortality of the control and NOAF groups were $9.1 \%$ and $20.8 \%$, respectively $(\mathrm{p}<0.001)$ (Fig. 2). Finally, univariate analysis revealed that NOAF, myocardial infarction, major stroke, major VC, major life-threatening bleeding, 2 valve implantation, AKI requiring hemodialysis, and AR $>2$ were significant predictors of 1-year mortality. Of these, NOAF [HR: 2.12, 95\%CI: 1.42-3.15, $\mathrm{p}<0.001]$, major and life threatening bleeding

[HR: 2.82, 95\%CI: 1.84-4.32, p<0.001], and AKI needing for hemodialysis [HR: 5.42, 95\%CI: 3.03-9.67, $\mathrm{p}<0.001$ ] were independently associated with an increased risk of 1-year mortality in the multivariate model (Table 6). 


\section{Discussion}

\section{1. Major findings}

Our study characterized the incidence, predictors and impact of NOAF on 30-day and 1-year prognosis after TAVI from the large multicenter FRANCE 2 registry. Consistent with our data, Généreux et al recently demonstrated the association between late bleeding, AF and mortality in TAVI patients. ${ }^{12}$ NOAF was observed in $7.6 \%$ of patients. The main results of the present study are as follows: 1) NOAF after TAVI was frequent; 2) advanced age, major and life-threatening bleeding after the index procedure were independently associated with an increased incidence of NOAF; 3) a trend towards a higher incidence of major life-threatening bleeding was observed in TA-approached TAVI patients; 4) NOAF was an independent predictor of 30-day and 1-year mortality.

\section{2. NOAF and TAVI device selection: CoreValve or SAPIEN?}

AF shares several predisposing factors with AS, such as advanced age and pulmonary 
hypertension. ${ }^{13}$ Consistent with our study, older population (age, $85 \pm 6$ years vs. $82 \pm 8$ years, $\mathrm{p}=0.001$ ), higher comorbidities (EuroSCORE, $23.1 \pm 2.2$ vs. $20.5 \pm 0.7, \mathrm{p}=0.021$ ) and higher PAP (43.6 \pm 13.9 vs. $47.7 \pm 14.9, \mathrm{p}=0.002$ ) were significantly associated with a higher incidence of NOAF. It is possible that elevated left ventricular chamber pressure is the cause of development of NOAF. But unfortunately we do not have the data about the cardiac pressures or mitral gradients. In a recent study ${ }^{5}$, the authors documented AF in $26 \%$ of the TAVI population whereas AF was identified in 39\% of our population. However, in the former study all patients with a documented history of AF were classified as AF patients ${ }^{5}$, whereas in our study, we also added in this category patients with extrasystole, atrial flutter and permanent pacemaker with AF. In the PARTNER (Placement of Aortic Transcatheter Valve) trial by Smith et al, ${ }^{14}$ patients were randomized to either TAVI using ES or SAVR. Including patients with a baseline history of AF, a significant difference in the development of NOAF after TAVI and SAVR (9\% vs. 16\%, respectively) was reported.

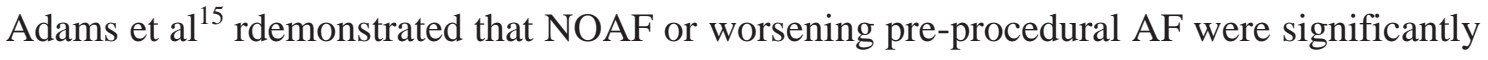
more common after SAVR when compared with TAVI using CV (31\% vs. 12\%, respectively). Both studies suggest that TAVI is more favorable for reducing the risk of 
NOAF compared to SAVR. However, only a few randomized studies have compared CV to ES and the incidence of NOAF. Furthermore, NOAF detection protocols in previous studies were diverse and often performed with continuous monitoring of varying duration, ranging between the first 3-7 days after the procedure or limited to the length of hospital-stay, with NOAF defined as a recorded AF episode lasting $>30$ seconds or 10 minutes. ${ }^{4,11,16}$ These variations in definition may further complicate the comparison between each observational study in reporting the incidence of NOAF after TAVI using CV and ES. In our study, the comparison was made implementing a unified definition to determine the incidence of NOAF. We have shown that the CV was significantly associated with a lower incidence of NOAF after TAVI compared to ES. This differential outcome could be partially explained by the procedural aspects of $\mathrm{CV}$ implantation, as the TA-approach results in a greater inflammatory response due to the surgical trauma involved compared with non-TA approaches which may predispose patients to NOAF. ${ }^{17}$ These findings need to be further investigated.

\section{3. NOAF and TAVI approach}


Independent predictive risk factors for postoperative AF have been reported in previous studies. ${ }^{18,}$ Particularly left atrial strain measurement has been evaluated as a promising tool to predict the post procedural NOAF. ${ }^{19}$ In contrast, the pathogenesis for NOAF following the less invasive TAVI procedure has so far not been well described, evidenced by the fact that AF has not been included within the guidelines for reporting mortality and morbidity after cardiac valve interventions. However, recently the VARC has drawn attention to AF following TAVI. ${ }^{20}$ In this context, there is limited data with regards to the differential incidence of AF associated with the various transcatheter approaches. The only previous prospective cohort evaluating NOAF in patients undergoing TAVI was recently reported by Amat-Santos et al. ${ }^{4}$ In this report, they described that NOAF occurred in about one-third of patients undergoing TAVI with no prior-AF and the incidence was increased in TAVI patients via the TA-approach. ${ }^{4}$ However, the incidence of NOAF in our study was much lower at 7.6\% compared with Amat-Santos et al (31.9\%). This discrepancy may in part be explained by the percentage of cases performed via the TA-approach. Whereas the TA-approach was predominantly used in the Amat-Santos' study (72\% of cases) ${ }^{4}$, the predominant approach in our study was the TF-approach, which may have contributed to 
the lower incidence of NOAF observed. Indeed, in the high-risk cohort of the PARTNER trial, which contained similar proportions of TF and TA approach as in our TAVI patients, NOAF occurred in only $8.6 \%$ of patients at 30 -days. ${ }^{14}$ The results of this study were comparable to our cohorts with respect to the proportion of cases performed via each approach. Our study, thus, demonstrated a difference in NOAF occurrence between two TAVI-approaches, confirming that the TA-approach was associated with a higher incidence of NOAF compared to the TF-approach. Recently, Rodés-Cabau et al ${ }^{21}$ reported that the TA-approach resulted in a higher increase of serum markers associated with myocardial injury, compared to the TF approach. This observation is consistent with our study supporting the hypothesis that the TA approach leads to more extensive myocardial injury, which in turn predisposes to a higher incidence of NOAF.

\section{4. Procedural bleeding and NOAF}

There is a limited range of data that has assessed the influence of post procedural bleeding and NOAF. Interestingly, our study revealed that post procedural major and life-threatening bleeding were independently associated with the development of NOAF. TA patients often 
are sicker and have a higher calcium burden over TF patients. Besides, in a recent study, Borz et al reported that the only independent predictor of life-threatening bleeding was the TA-approach. ${ }^{22}$ In addition, Amat-Santos et al reported that the TA-approach, which is considered as a predictive factor for NOAF, can lead to peri-procedural systemic inflammation, direct pericardial inflammation, and a hyper-adrenergic state related to the stress of the surgical procedure and post-operative pain. ${ }^{4}$ These issues may support an interplay between NOAF and bleeding events following the TA-approach, which was observed in our study, suggesting that, it may be possible to reduce these adverse events by limiting the TA approach. Besides the reduction in the occurrence of NOAF, our study demonstrated an additional benefit in using non TA approaches such-that there was a significant shortening of the ICU-stay length and hospital-stay length post-procedure.

\section{5. Predictive value of mortality following TAVI}

In a study by Ruel et al, ${ }^{23}$ thromboembolic stroke occurred in $6.7 \%$ of patients undergoing SAVR post-procedure, and AF was an independent predictor of stroke. Furthermore, mortality during the 10 -year follow-up was found to increase by $48 \%$ in patients with 
NOAF compared to patients without NOAF after SAVR. ${ }^{11}$ In contrast with TAVI, to date there have been few reports focusing on NOAF in relation to the mortality post-procedure. ${ }^{4}$ In the study by Amat-Santos et $\mathrm{al}^{4}$, no increase in the mortality rate of NOAF patients compared with non-NOAF patients was reported. In contrast, our study revealed that the mortality rate increased significantly and independently in patients with NOAF at 1-year post-TAVI. This discrepancy may be partly explained by the study limitations of previous series including small sample sizes. Additionally, we found that stroke was associated with an increased mortality at 30-days, suggesting that in our TAVI cohort, there is a similar association between NOAF, stroke, and increased mortality. In an observational study by Nombela-Franco et al, ${ }^{24}$ almost $50 \%$ of cerebrovascular events (defined as transient ischemic attack or stroke) occurred $>24$ hours after TAVI. This suggests that cerebrovascular events are not exclusively peri-procedural complications, but may also be related to clinical factors, such as NOAF. In addition, they reported that patients who developed NOAF after TAVI had a significantly increased risk of cerebrovascular events during the subacute period of days 1-30. This observation is consistent with our findings that stroke is an independent predictor of mortality at 30-days. 


\section{6. Study limitations}

The findings of this present study have several limitations. The FRANCE 2 registry is a nonrandomized clinical investigation. Therefore, differences in baseline clinical parameters exist. Additionally, NOAF detection was performed with continuous monitoring of varying duration limited to the length of hospital stay, thus there is the risk of underestimating the true incidence of NOAF as episodes occurring after discharge will have been undetected. Moreover, patients with sinus rhythm at baseline were not all free of a prior history of AF. On the contrary, NOAF was defined as a recorded AF episode lasting $>30$ seconds on a rhythm strip, hence there is also the risk of overestimating the incidence of NOAF as clinically relevant AF may require longer episodes of AF to be recorded. Furthermore we unfortunately could not adjust for analysis relating the duration of AF to stroke or mortality, as the characteristics of AF (paroxysmal or permanent) were not mentioned in our registry. As our study is based on a real world clinical data set, informative diagnostic information to define precisely durations and episodes of AF were not always available. In addition, the data for the management of NOAF could not be adjusted for differences in pharmacologic 
treatment owing to the limited information available. Particularly the prevalence of patients treated during the mid or long term follow-up with anticoagulation or beta-blockers after the procedure was not mentioned. Then these therapies could have interfered with our results. However these drugs are intrinsically associated with NOAF as there are parts of the usual treatment of this disease. Indeed, TAVI practices were not uniform among centers and may have been modified over the study inclusion time and follow-up. Data on the number of procedures and survival outcomes were relatively robust in the TAVI-cohort, whereas there was insufficient power to determine differences in the management of our patients with NOAF.

\section{Conclusion}

In conclusion, age, major or life-threatening bleeding are independently associated with an increased incidence of NOAF, which is an independent predictor of 30-days and 1-year mortality. With regard to the various transcatheter approaches, a trend towards a higher incidence of major and life-threatening bleeding was only observed in the TA-approach. 
Then in high-risk TAVI patients potentially associated with the risk of bleeding, especially in the TA-approach, pre-procedural anti-arrhythmic drug could be used to prevent NOAF and consequently reduce the post-TAVI mortality. Further studies are needed to validate this hypothesis.

\section{Conflict of interest}

There is no conflict of interest to declare for this manuscript. 


\section{Reference}

1. Leon M.B, Smith C.R, Mack M, et al. Transcatheter aortic-valve implantation for aortic stenosis in patients who cannot undergo surgery. N. Engl. J. Med 2010; 363 :1597-1607

2. Van der Werf H.W, Douglas Y.L, Van den Heuvel A.F.M. TAVI in heart failure, how much risk is acceptable? Eur. J. Heart Fail 2012; 14 (10): 1087-1089

3. Gilard M, Eltchaninoff H, Iung B, et al. Registry of transcatheter aortic-valve implantation in high-risk patients. N. Engl. J. Med.2012; 366: 1705-1715

4. Amat-Santos IJ, Rodés-Cabau J, Urena M, et al. Incidence, Predictive Factors, and Prognostic Value of New-Onset Atrial Fibrillation Following Transcatheter Aortic Valve Implantation. J Am Coll Cardiol. 2012; 59(2): 178-188.

5. Chopard R, Teiger E, Meneveau N et al. Baseline Characteristics and Prognostic Implications of Pre-Existing and New-Onset Atrial Fibrillation After Transcatheter Aortic Valve Implantation: Results From the FRANCE-2 Registry. JACC Cardiovasc Interv. 2015; 24: 8(10): 1346-55.

6. Murdock D.K., Rengel L.R., Schlund A. Stroke and atrial fibrillation following cardiac surgery. WMJ. 102 2003:26-30. 
7. Wann L.S., Curtis A.B., Ellenbogen K.A.; 2011 ACCF/AHA/HRS focused update on the management of patients with atrial fibrillation (updating the 2006 guideline): a report of the American College of Cardiology Foundation/American Heart Association Task Force on Practice Guidelines. J Am Coll Cardiol. 57 2011:223-242.

8. Horlocker T.T., Wedel D.J., Rowlingson J.C.; Regional anesthesia in the patient receiving antithrombotic or thrombolytic therapy: American Society of Regional Anesthesia and Pain Medicine evidence-based guidelines. Reg Anesth Pain Med. 35 2010:64-101.

9. Gilard M, Eltchaninoff H, Iung B, et al. Registry of transcatheter aortic-valve implantation in high-risk patients. N Engl J Med 2012; 366:1705-1715.

10. Kappetein A.P, Head S.J, Généreux P, et al. Updated standardized endpoint definitions for transcatheter aortic valve implantation: the Valve Academic Research Consortium-2 consensus document. Eur. J. Cardiothorac. Surg 2012; 42 (5): S45-S60.

11. Filardo G, Hamilton C, Hamman B, et al. New-onset postoperative atrial fibrillation and long-term survival after aortic valve replacement surgery. Ann Thorac Surg. 2010;90(2):474-479. 
12. Généreux P, Cohen DJ, Mack M, et al. Incidence, Predictors, and Prognostic Impact of Late Bleeding Complications After Transcatheter Aortic Valve Replacement. J Am Coll Cardiol. 2014;64(24):2605-2615.

13. Stewart BF, Siscovick D, Lind BK, et al. Clinical factors associated with calcific aortic valve disease. Cardiovascular Health Study. J Am Coll Cardiol. 1997;29(3):630-634.

14. Smith CR, Leon MB, Mack MJ, et al. Transcatheter versus surgical aortic-valve replacement in high-risk patients. N Engl J Med. 2011;364(23):2187-2198.

15. Adams DH, Popma JJ, Reardon MJ, et al. Transcatheter aortic-valve replacement with a self-expanding prosthesis. N Engl J Med. 2014;370(19):1790-1798.

16. Nuis RJ, Van Mieghem NM, Schultz CJ, et al. Frequency and causes of stroke during or after transcatheter aortic valve implantation. Am J Cardiol. 2012;109(11):1637-1643.

17. Nattel S, Burstein B, Dobrev D. Atrial remodeling and atrial fibrillation: mechanisms and implications. Circ Arrhythm Electrophysiol. 2008;1(1):62-73.

18. Mathew JP, Fontes ML, Tudor IC, et al. A multicenter risk index for atrial fibrillation after cardiac surgery. JAMA 2004, 291(14):1720-1729. 
19. de Vito, R., Di Giovanni, A., Reccia, R., Di Tommaso, C., Bigio, E., Focardi, M., Cameli, M., \& Mondillo, S. Left atrial strain predicts postoperative atrial fibrillation in patient undergoing major orthopaedic surgery. International Cardiovascular Forum Journal. 2014;1:189-192.

20. Akins CW, Miller DC, Turina MI et al. Guidelines for reporting mortality and morbidity after cardiac valve interventions. J Thorac Cardiovasc Surg. 2008 ; 135(4): 732-738.

21. Rodes-Cabau J, Gutierrez M, Bagur R, et al. Incidence, predictive factors, and prognostic value of myocardial injury following uncomplicated transcatheter aortic valve implantation. J Am Coll Cardiol. 2011;57(20):1988-1999.

22. Borz B, Durand E, Godin M, et al. Incidence, predictors and impact of bleeding after transcatheter aortic valve implantation using the balloon-expandable Edwards prosthesis. Heart. 2013 ;99(12):860-5.

23. Ruel M, Masters RG, Rubens FD, et al. Late incidence and determinants of stroke after aortic and mitral valve replacement. Ann Thorac Surg. 2004;78(1):77-83; discussion, 83-84. 
24. Nombela-Franco L, Webb JG, de Jaegere PP, et al. Timing, predictive factors, and prognostic value of cerebrovascular events in a large cohort of patients undergoing transcatheter aortic valve implantation. Circulation. 2012;126(25):3041-3053.

Figure 1. Mortality at 30-day follow up 
Figure 1. Mortality at 30-day follow up

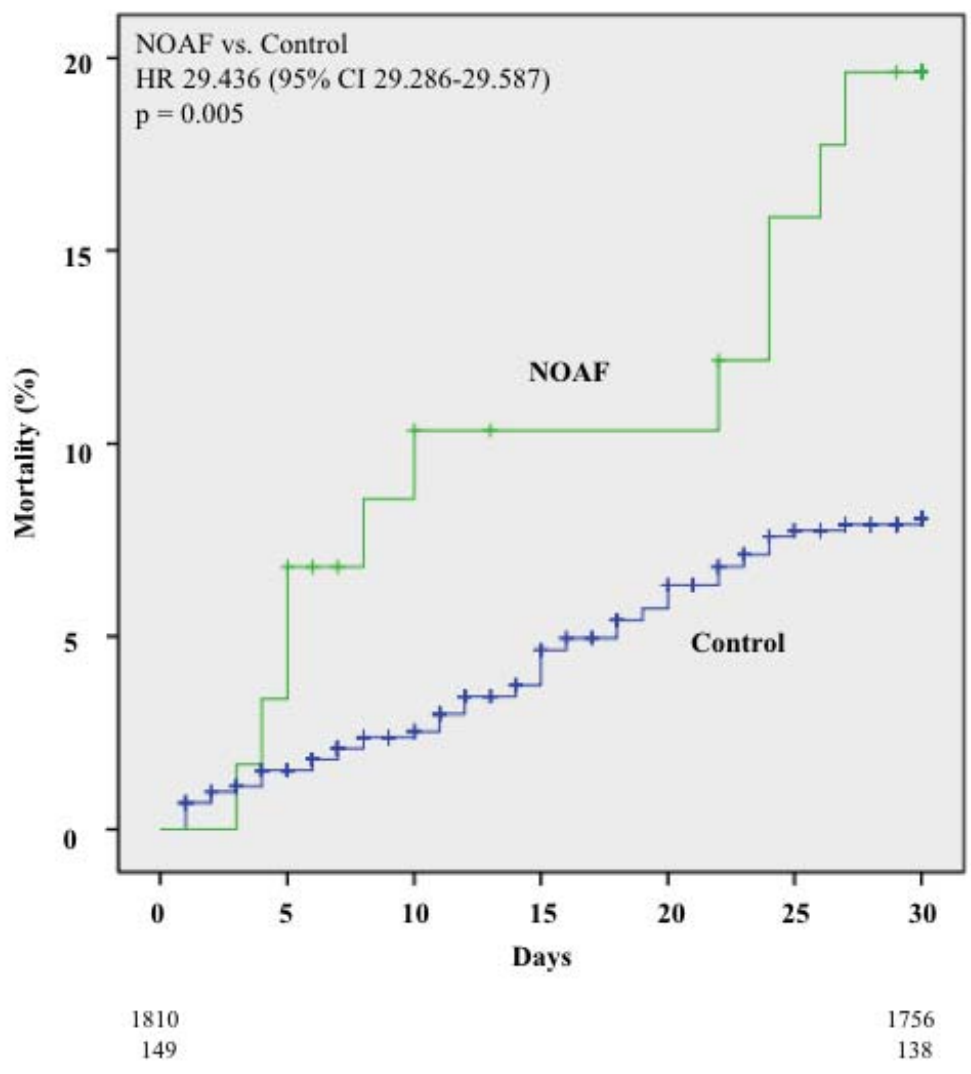


Figure 2. Mortality at 1-year follow up

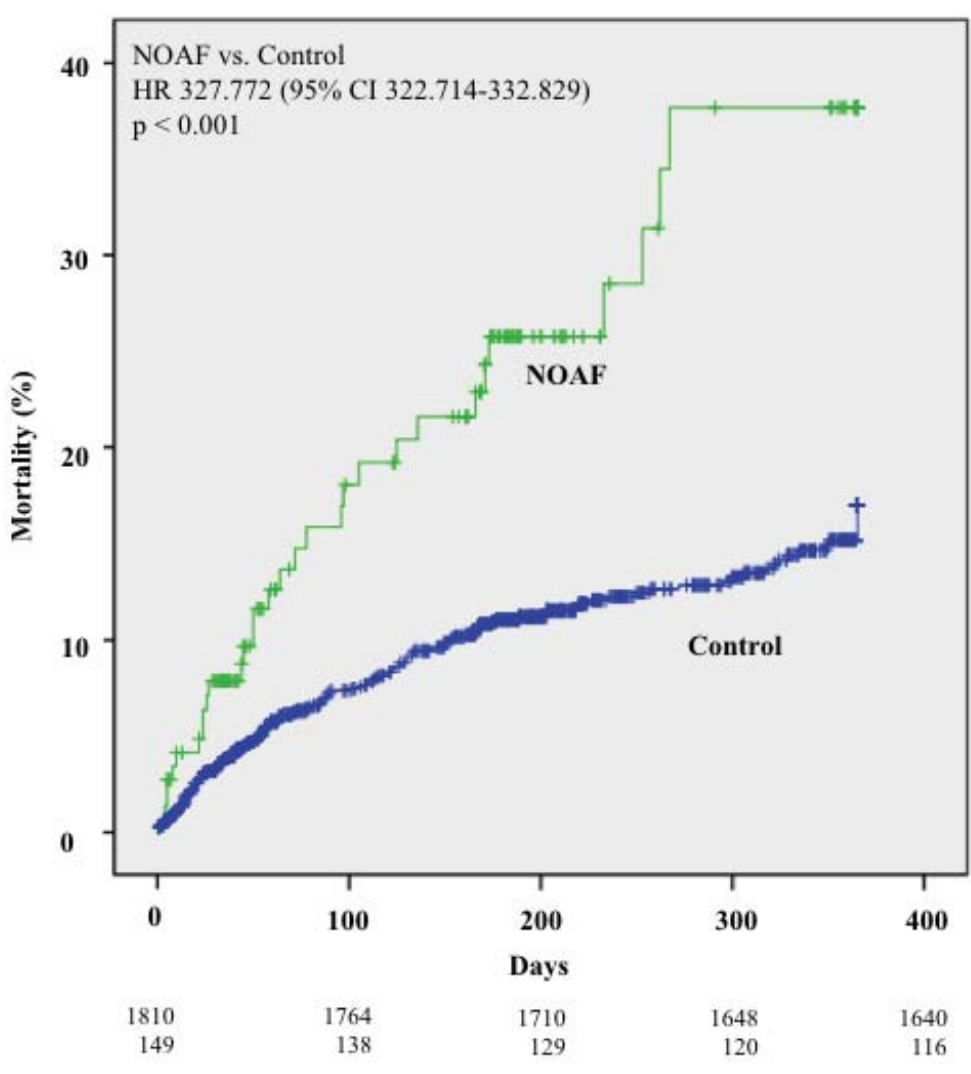

Figure 2. Mortality at 1-year follow up 


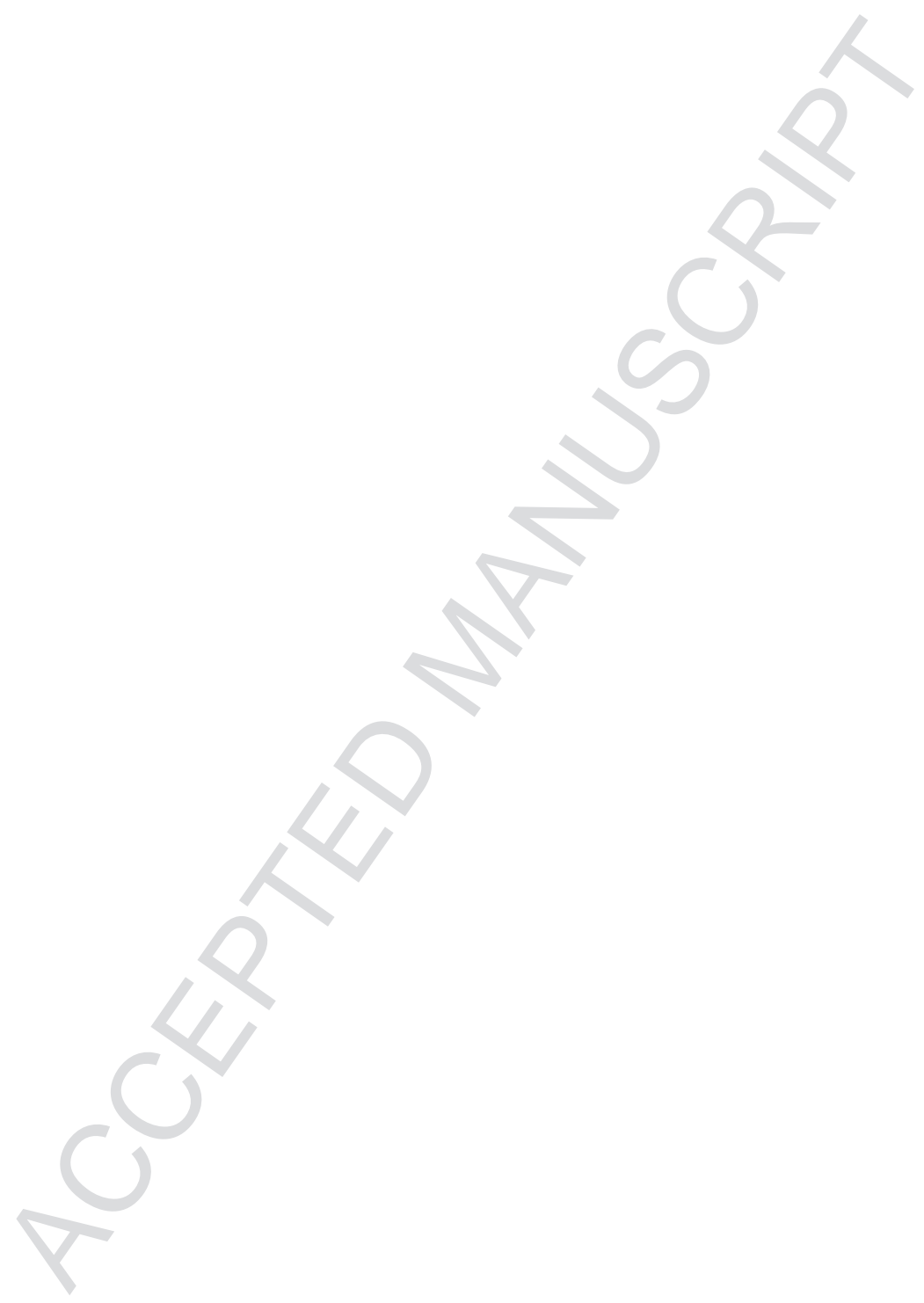




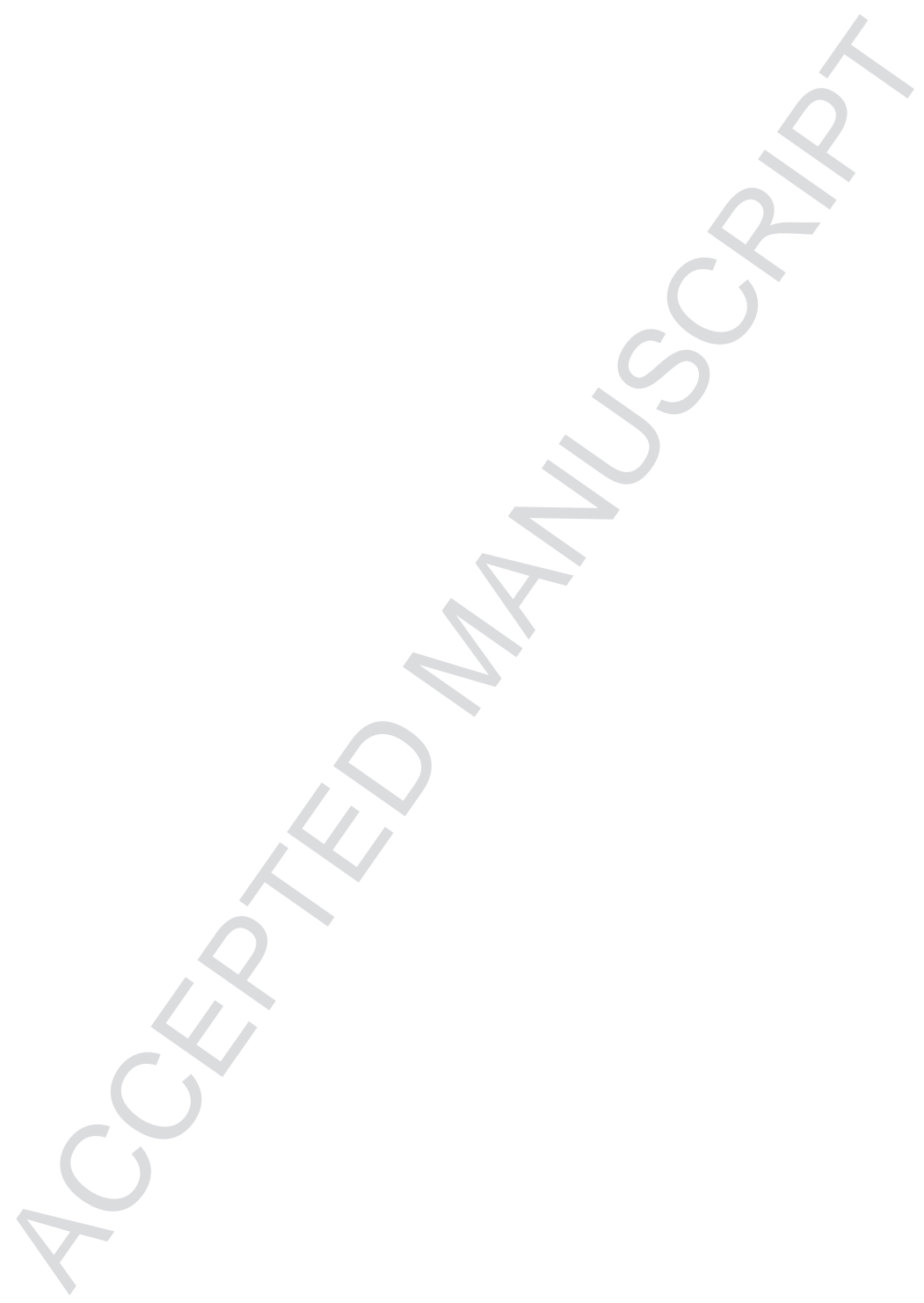




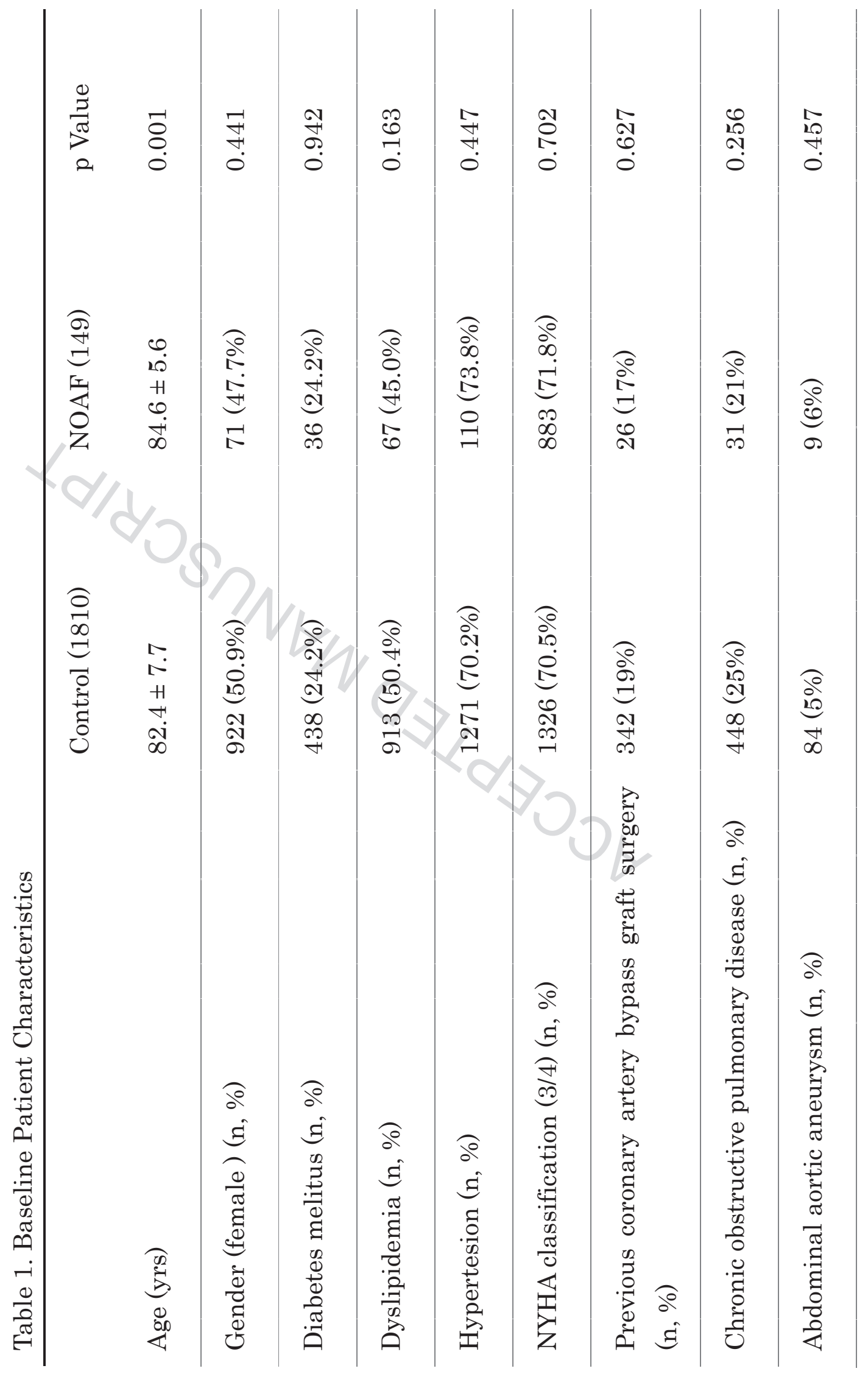




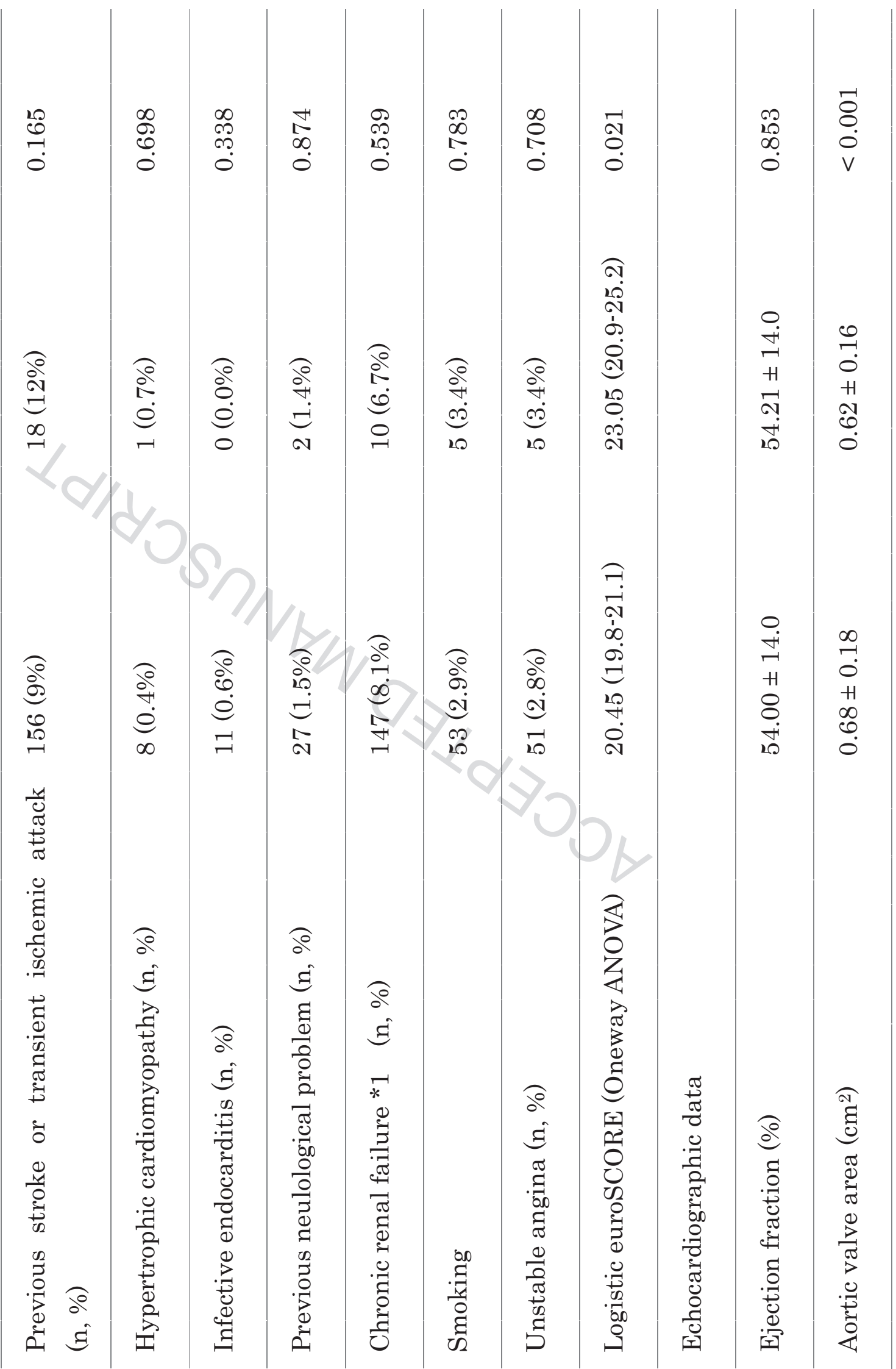




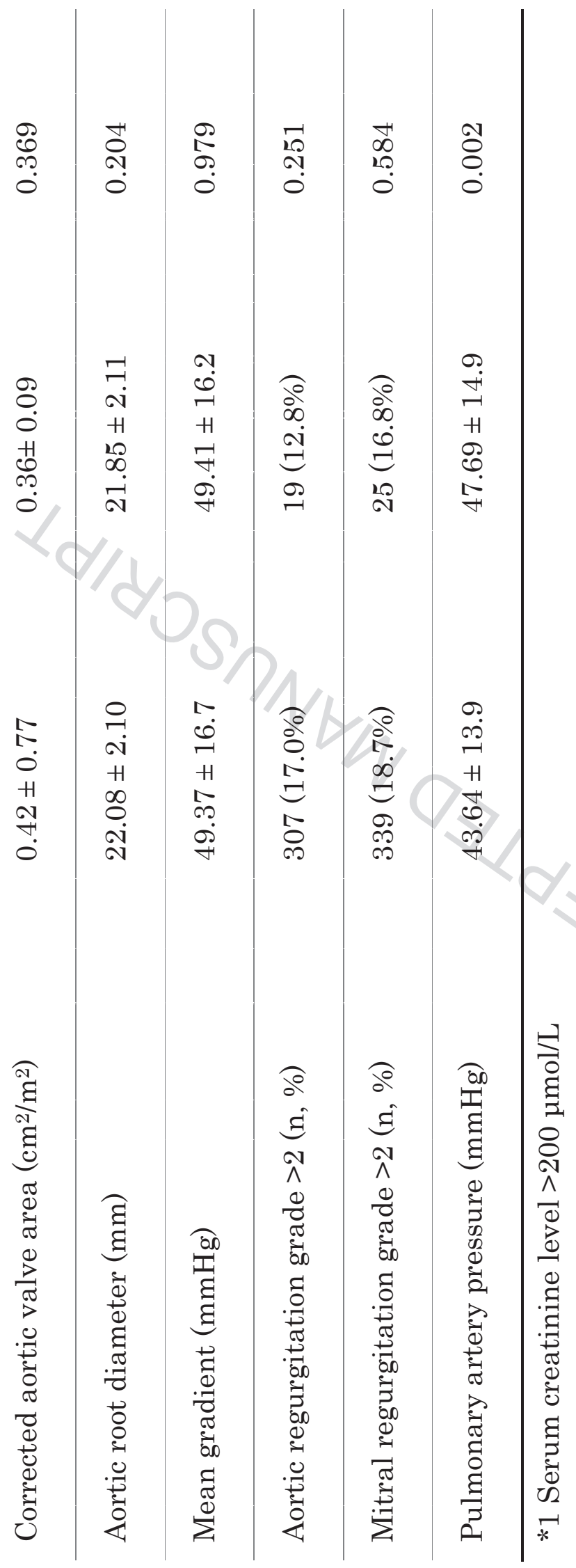


ค)

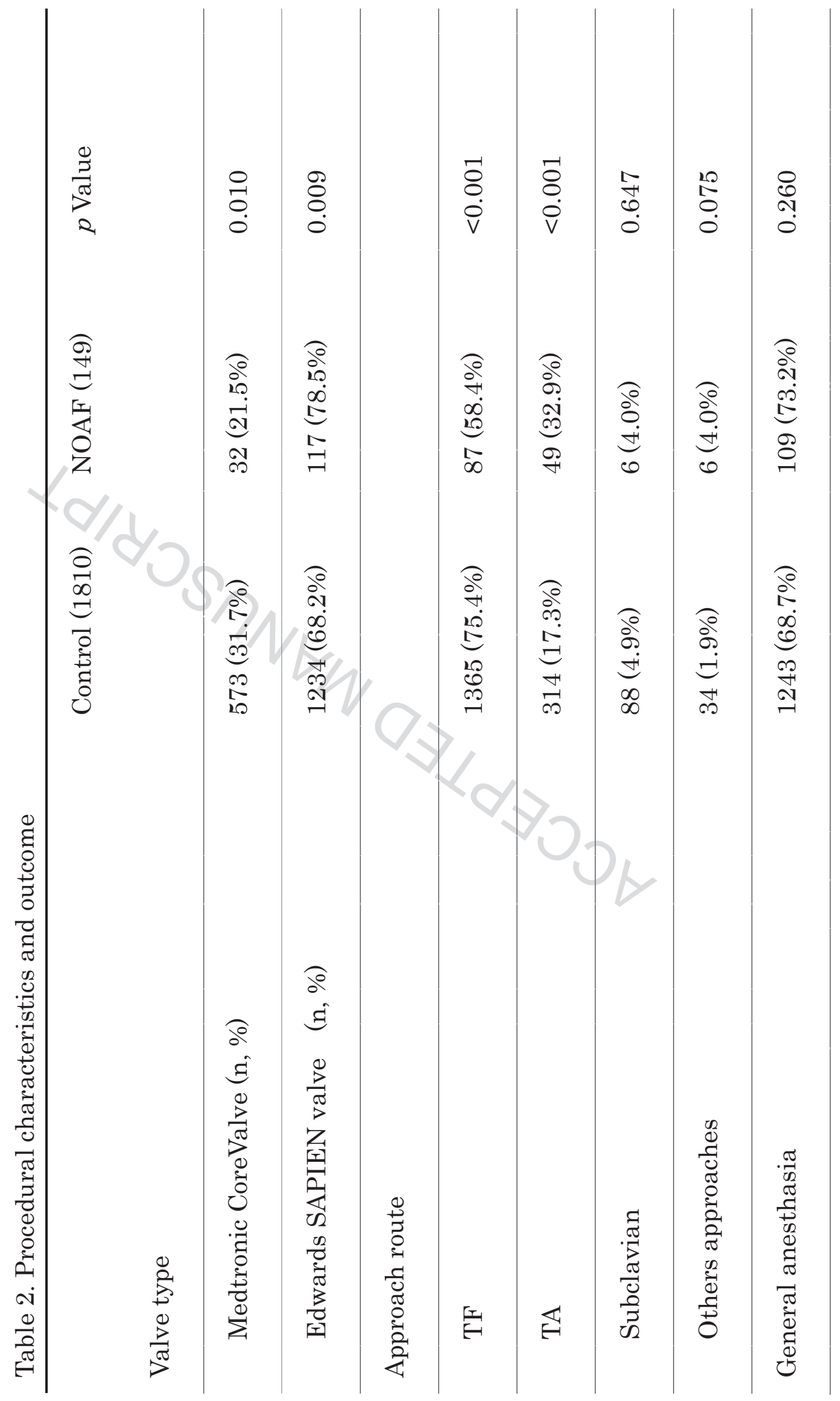


$\stackrel{ }{\forall}$

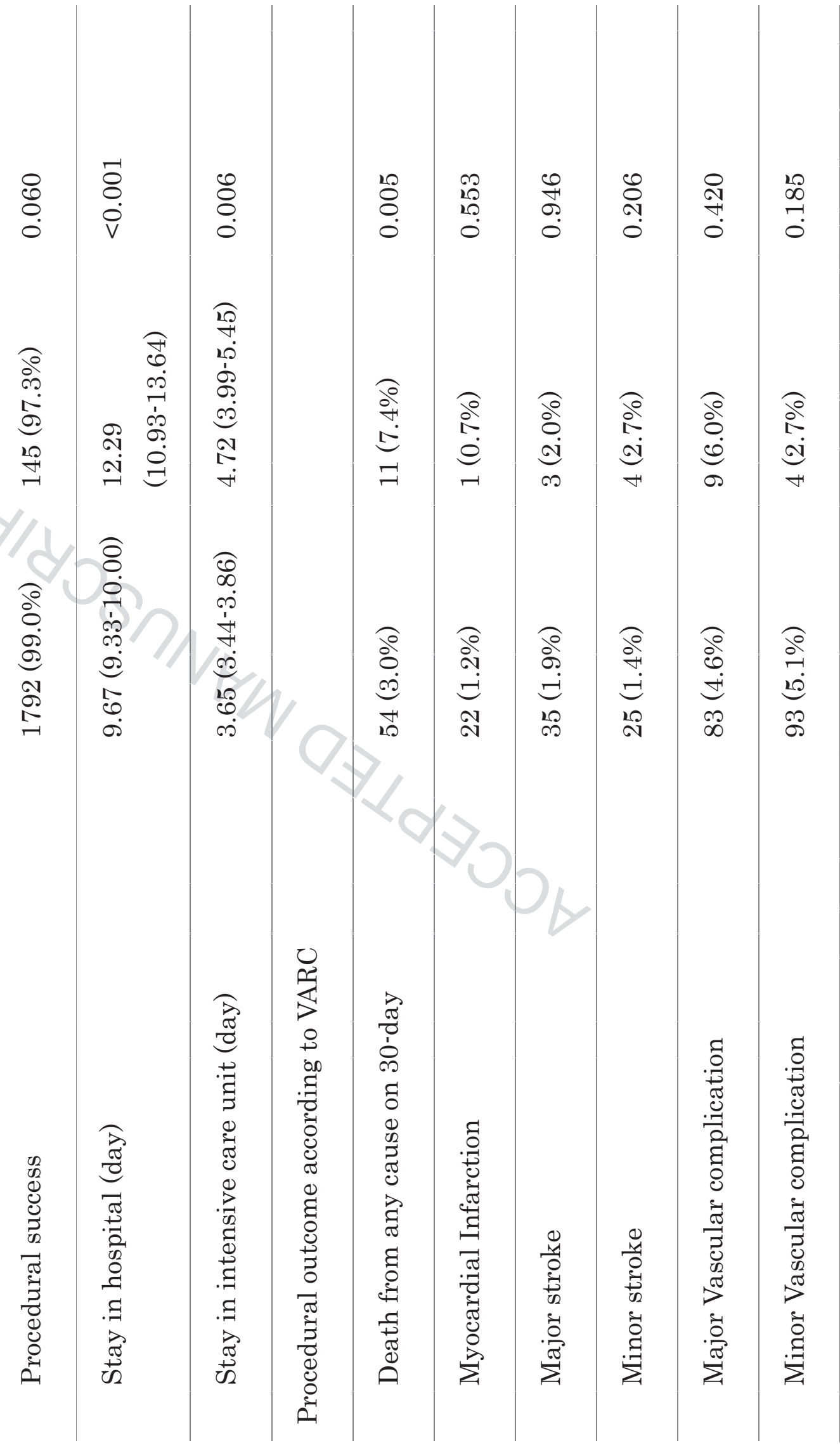




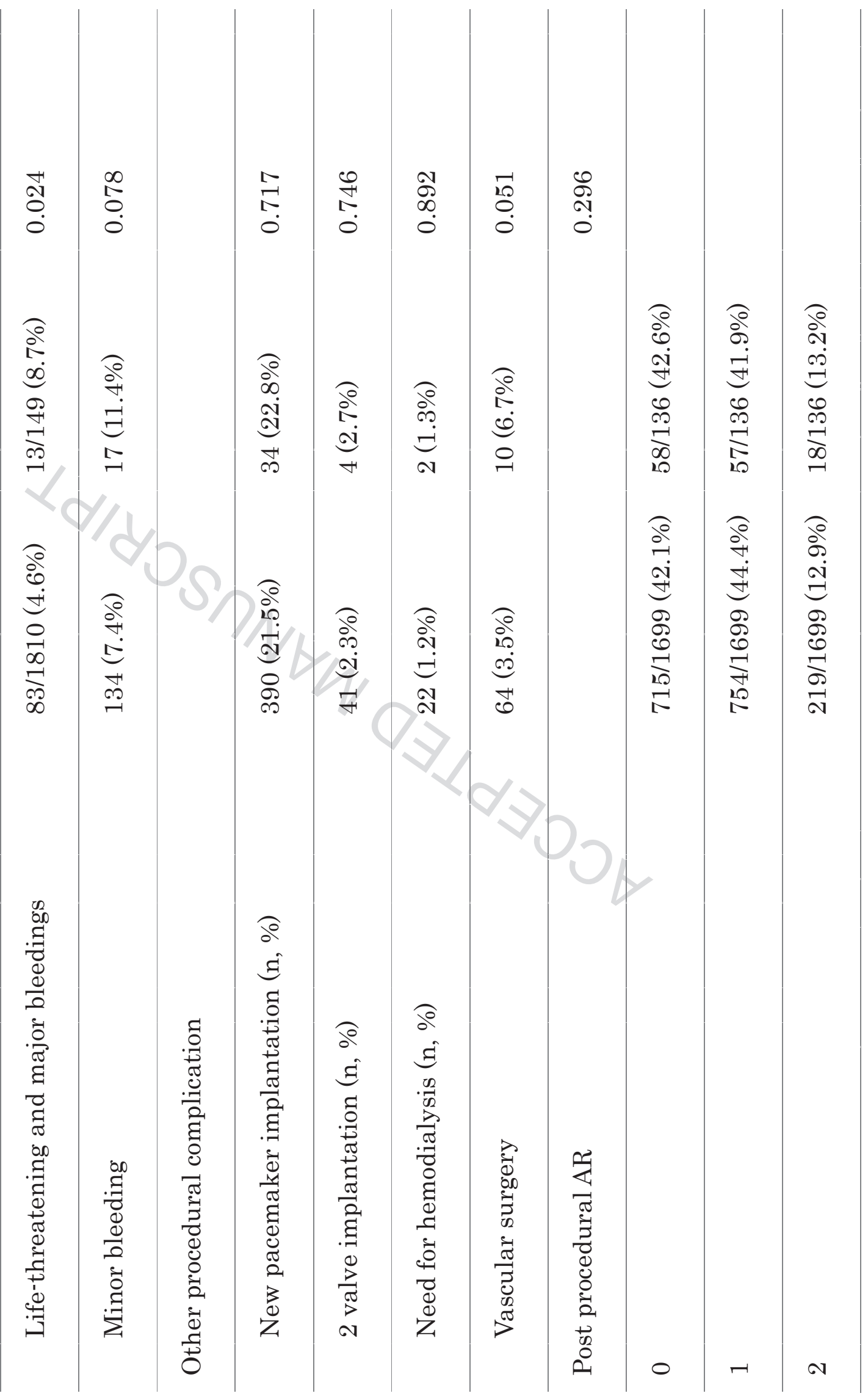




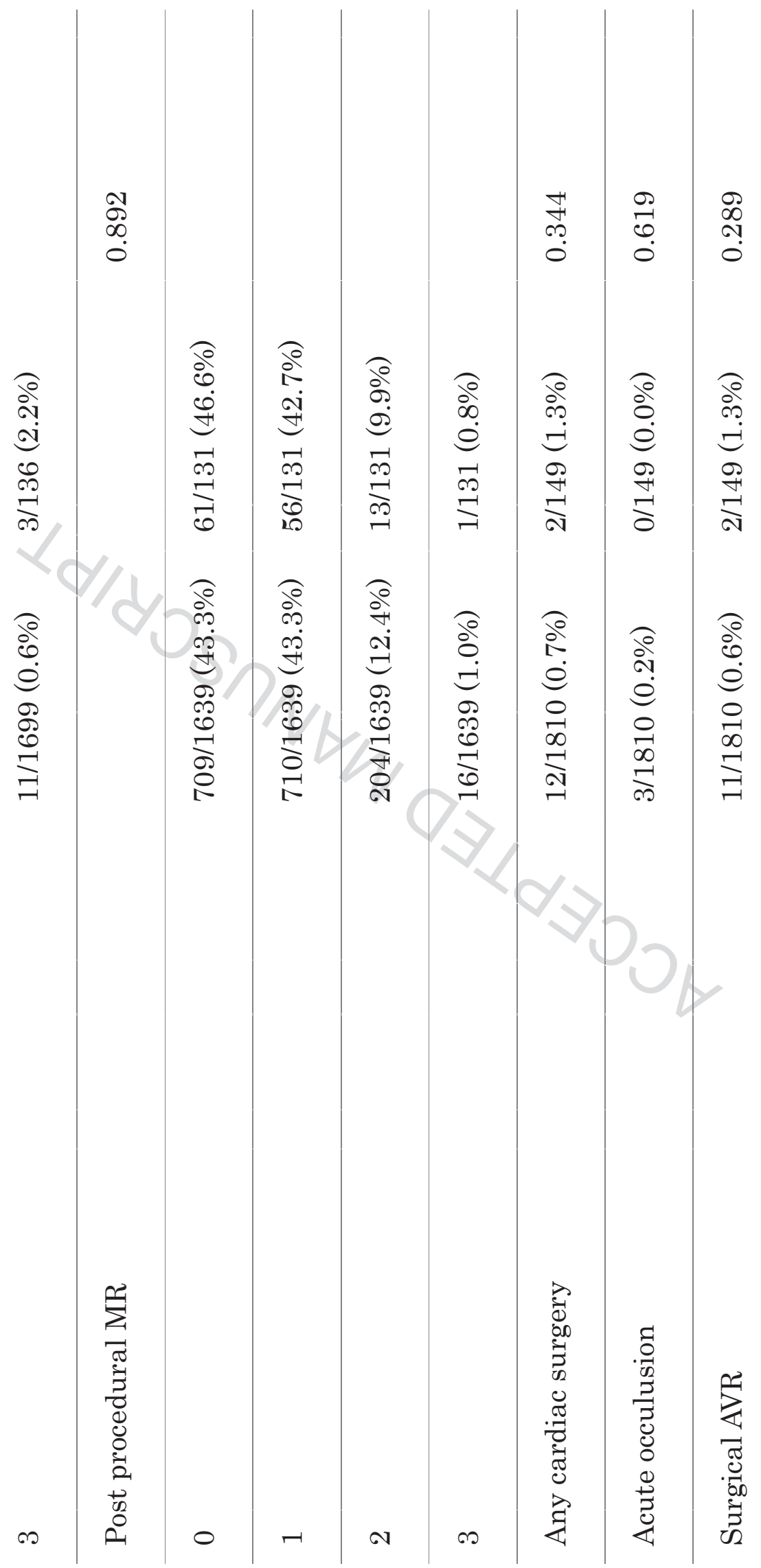


甶

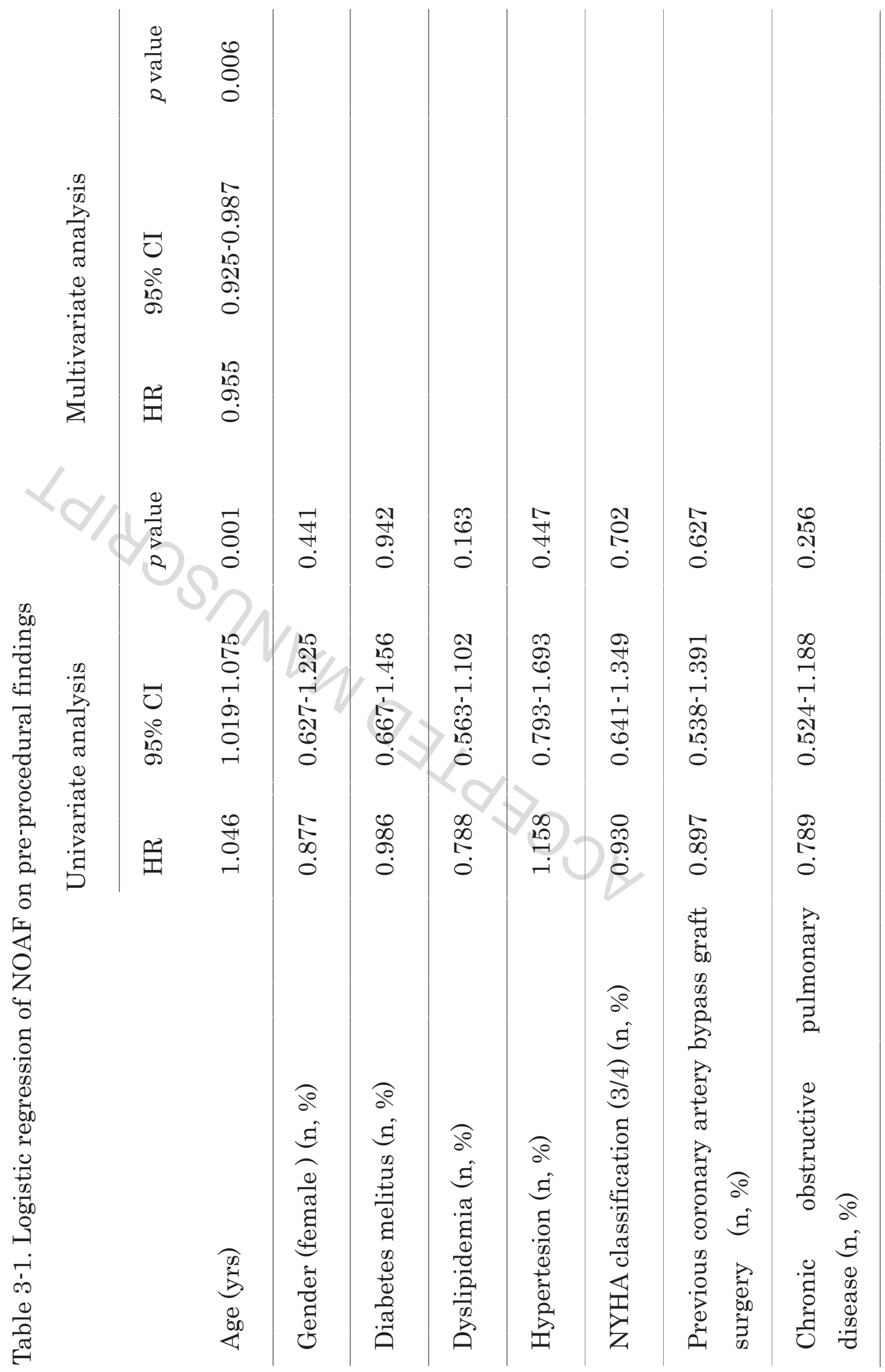




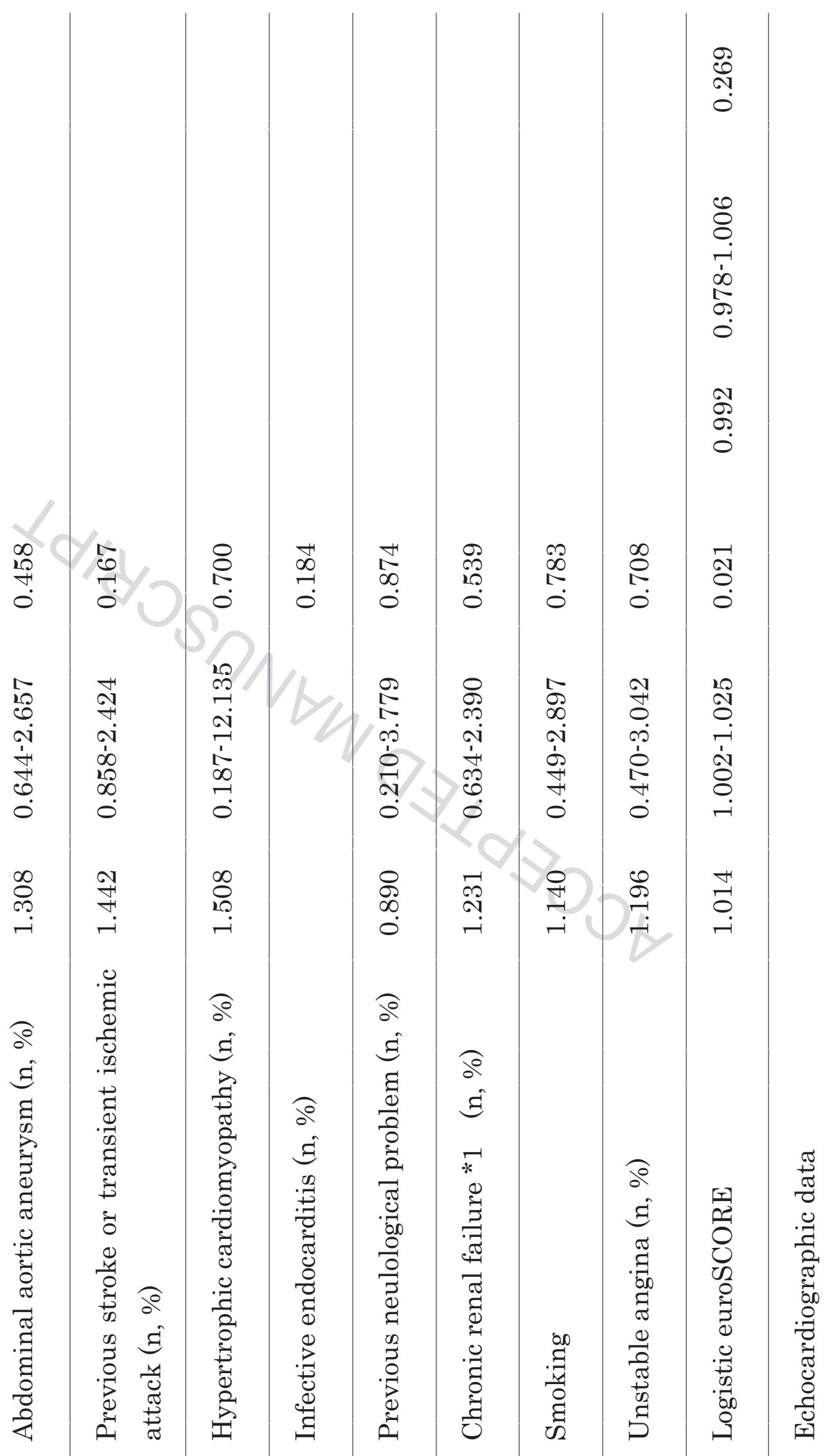




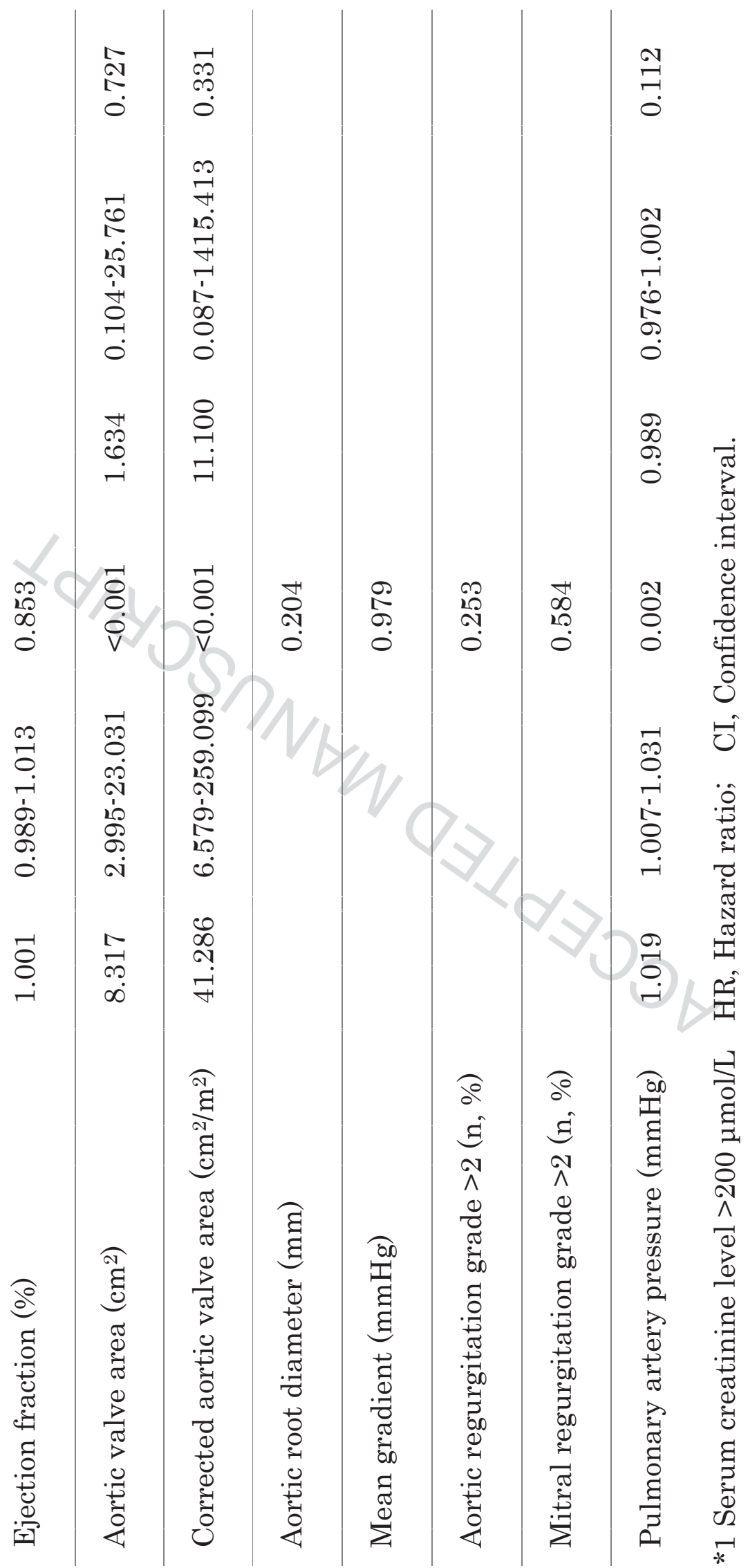




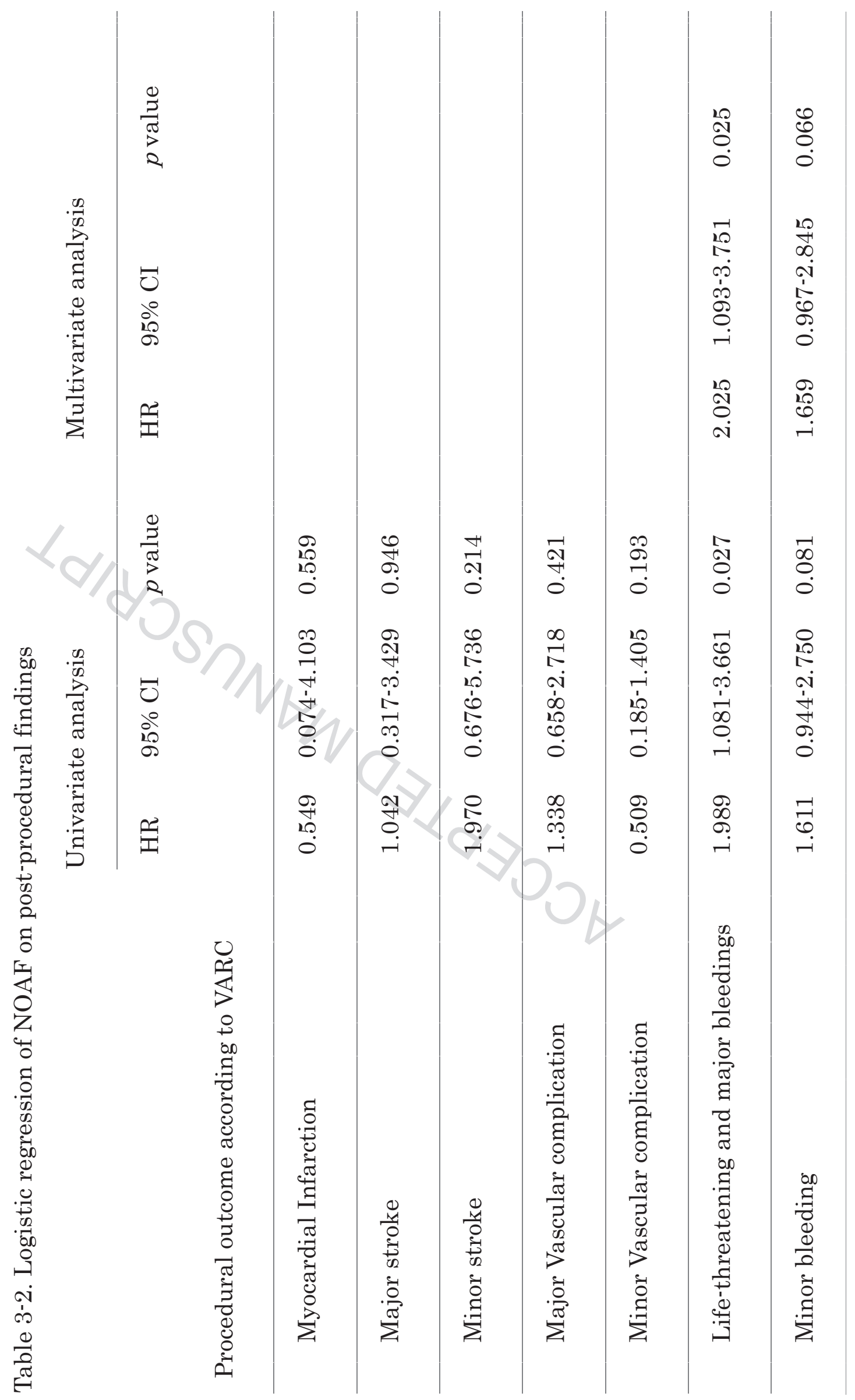




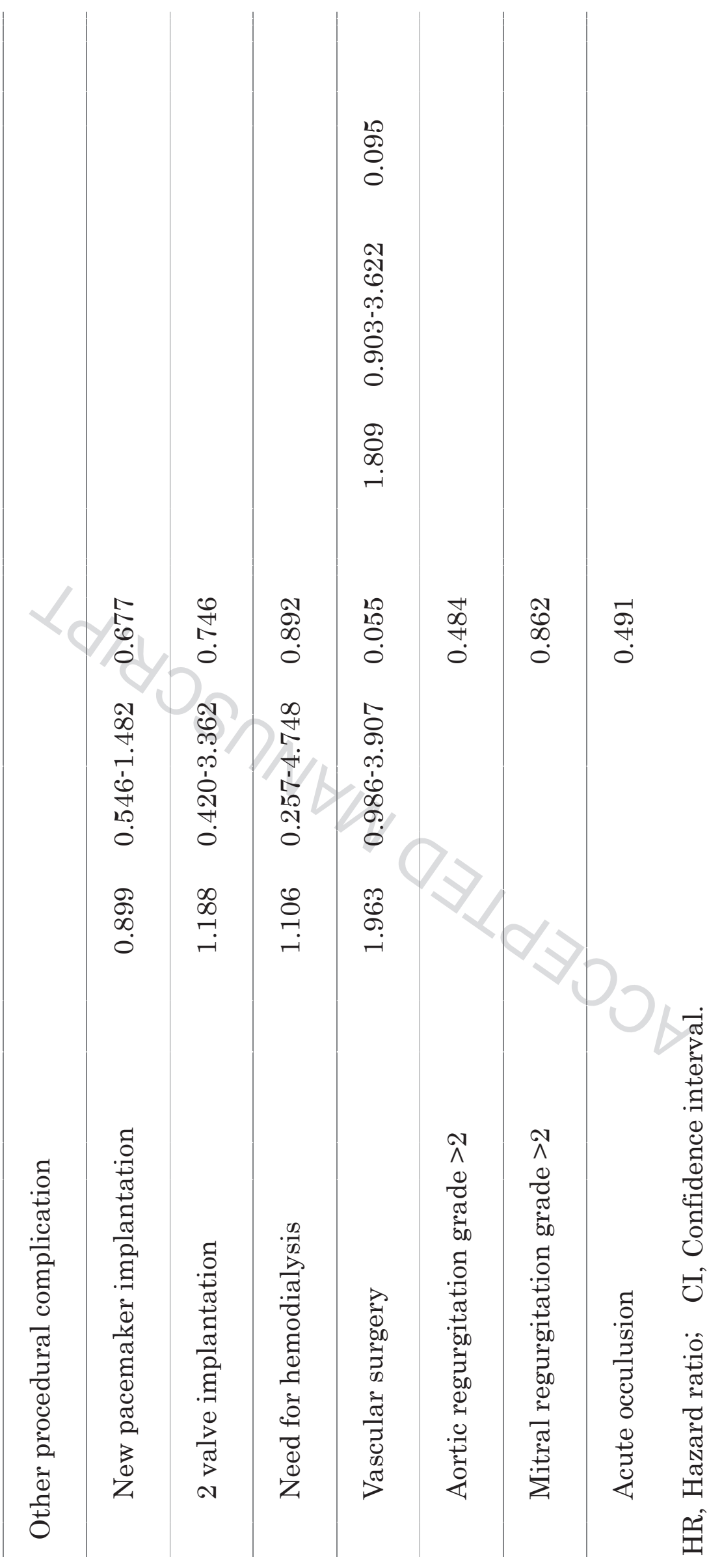




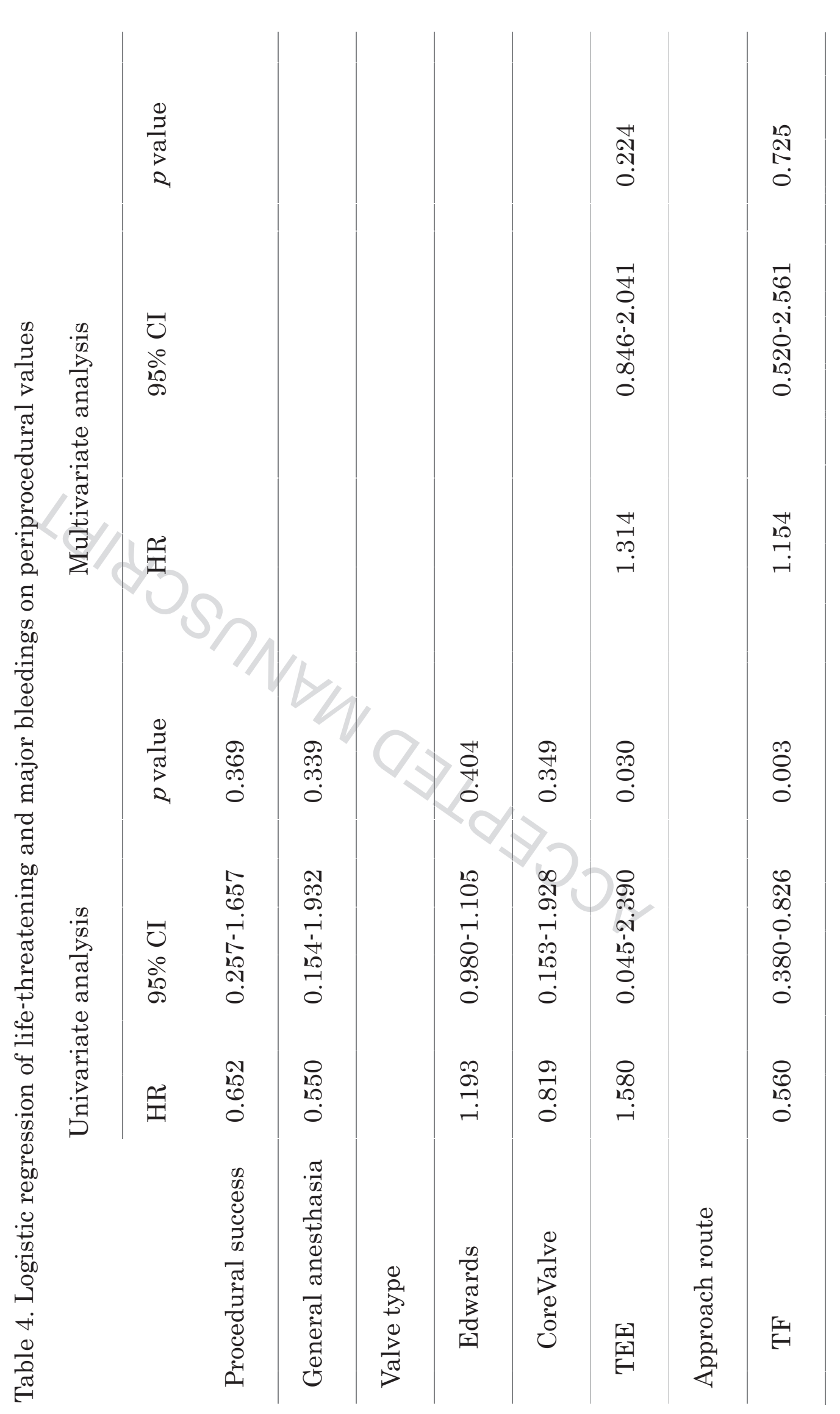




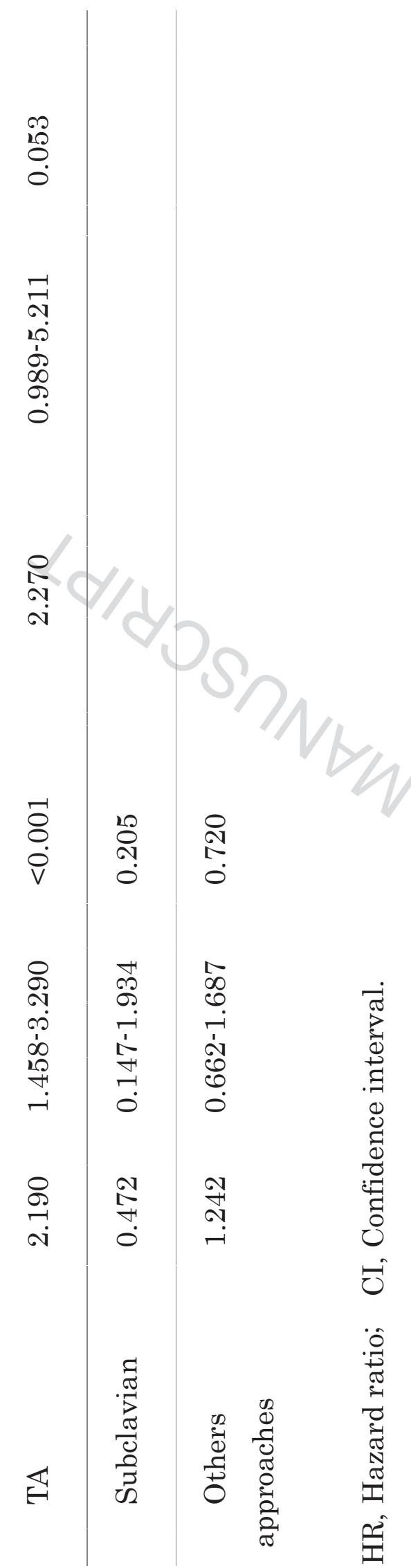




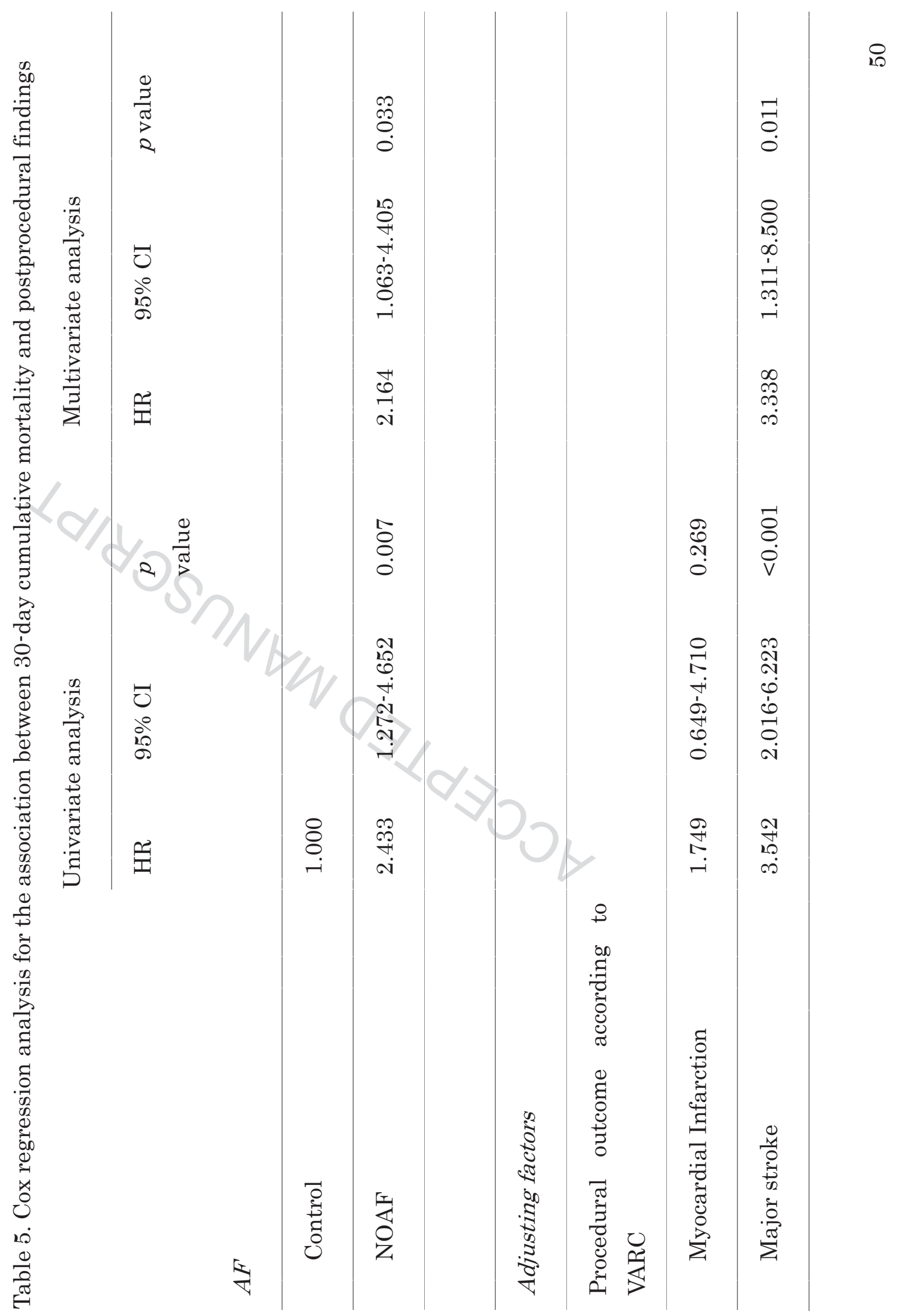




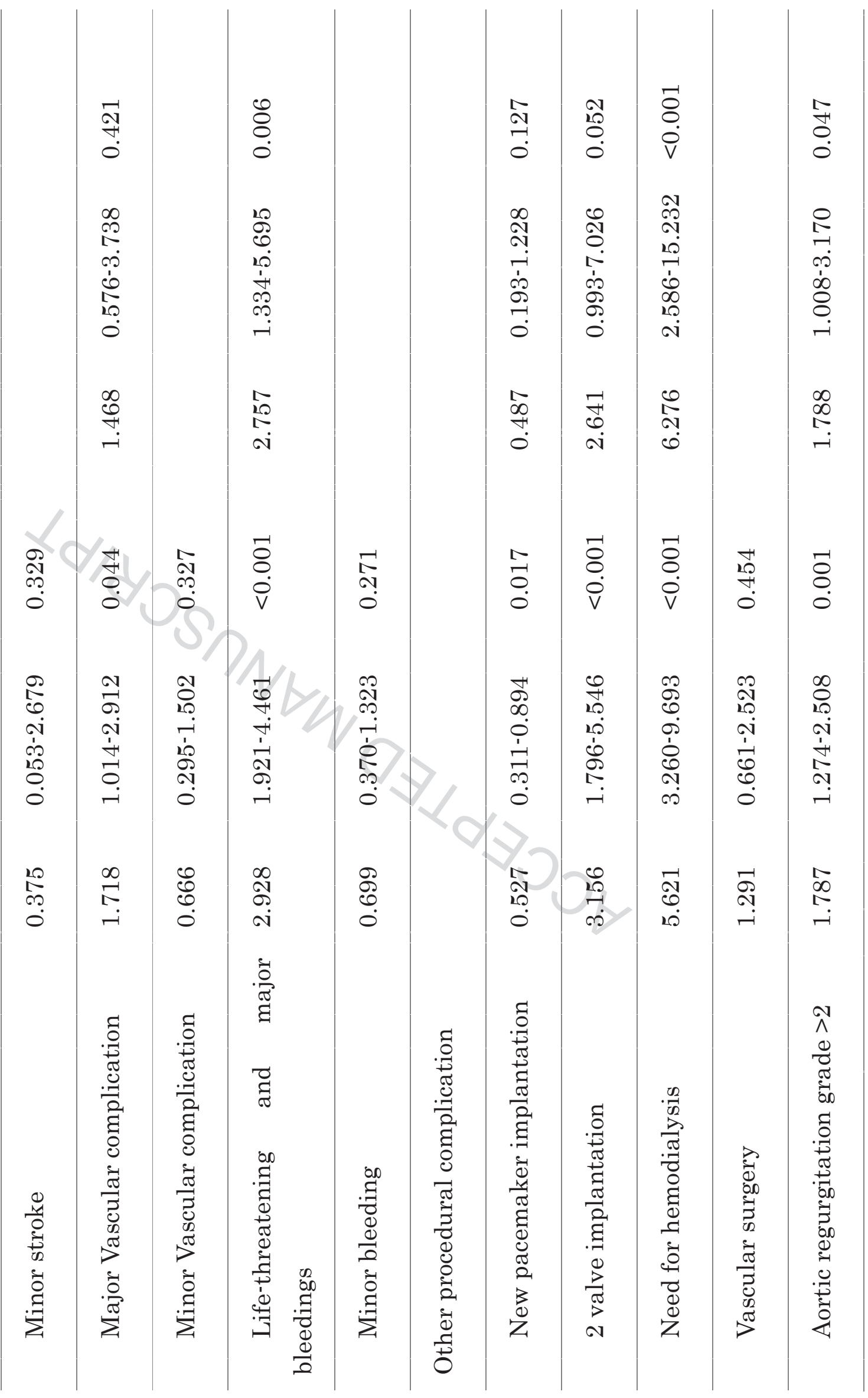




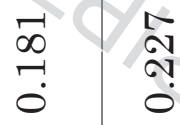

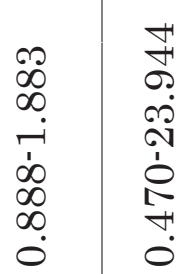

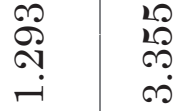

$\stackrel{N}{\wedge}$

$\frac{0}{0}$

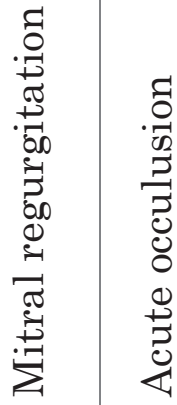




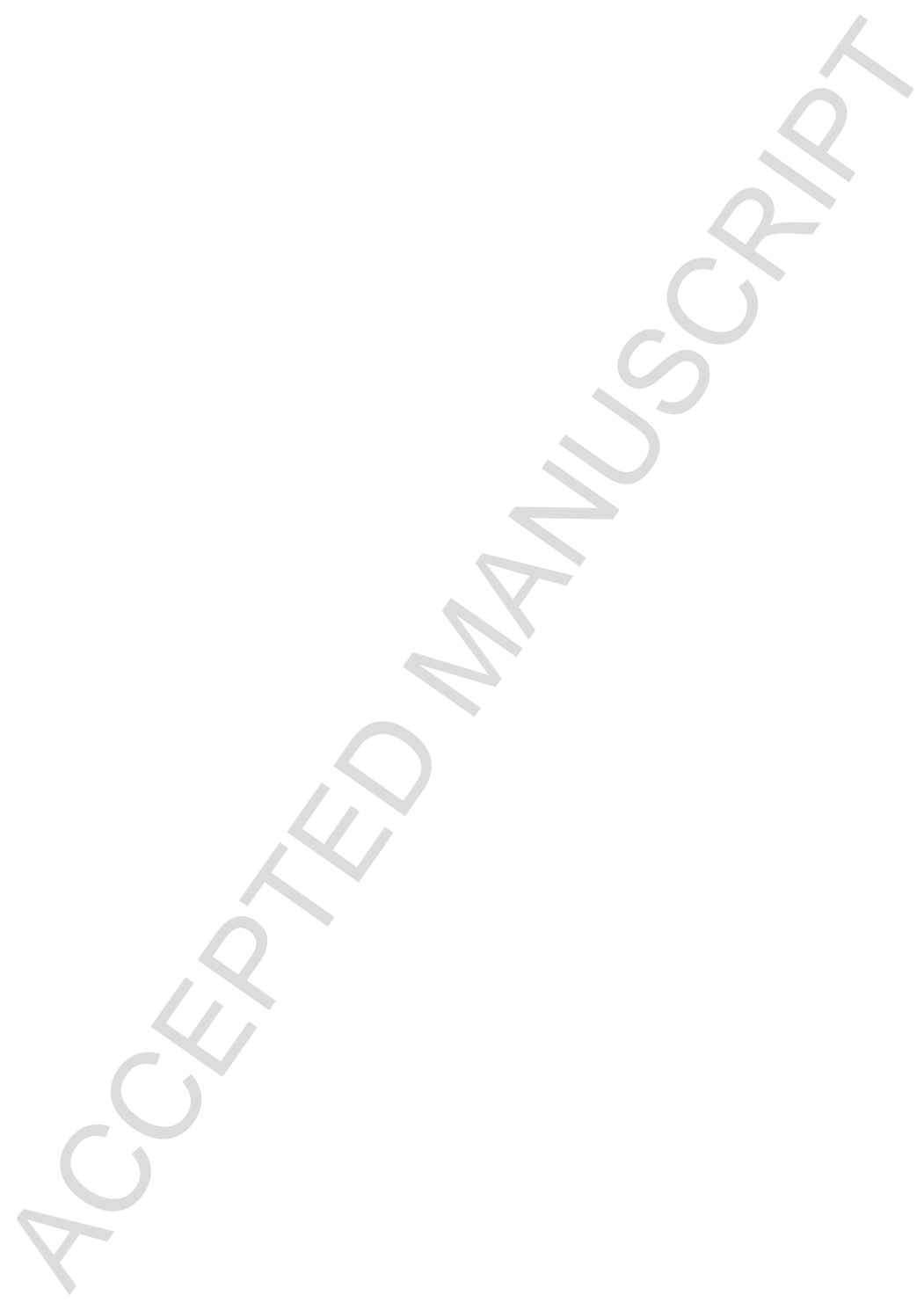




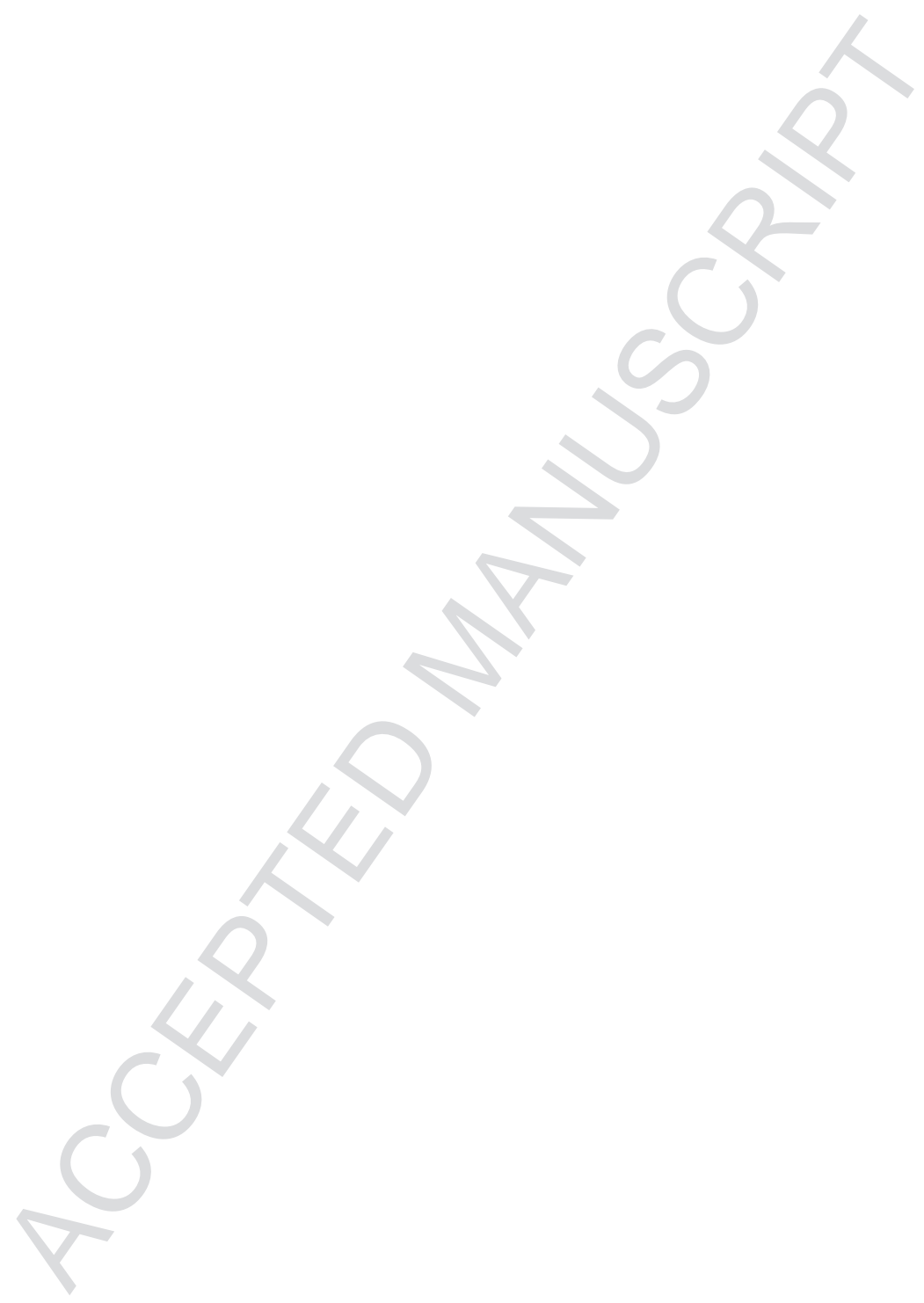




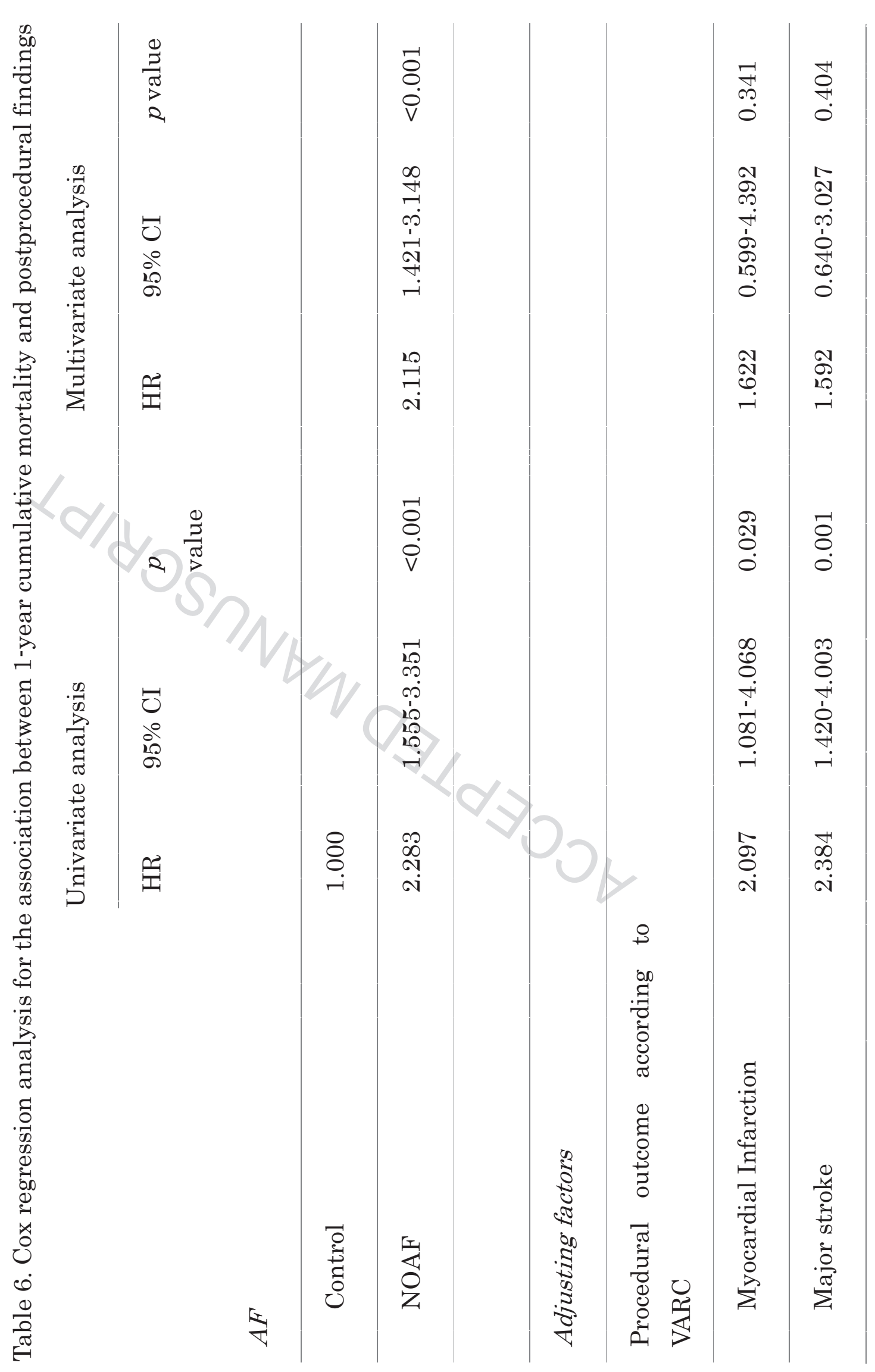




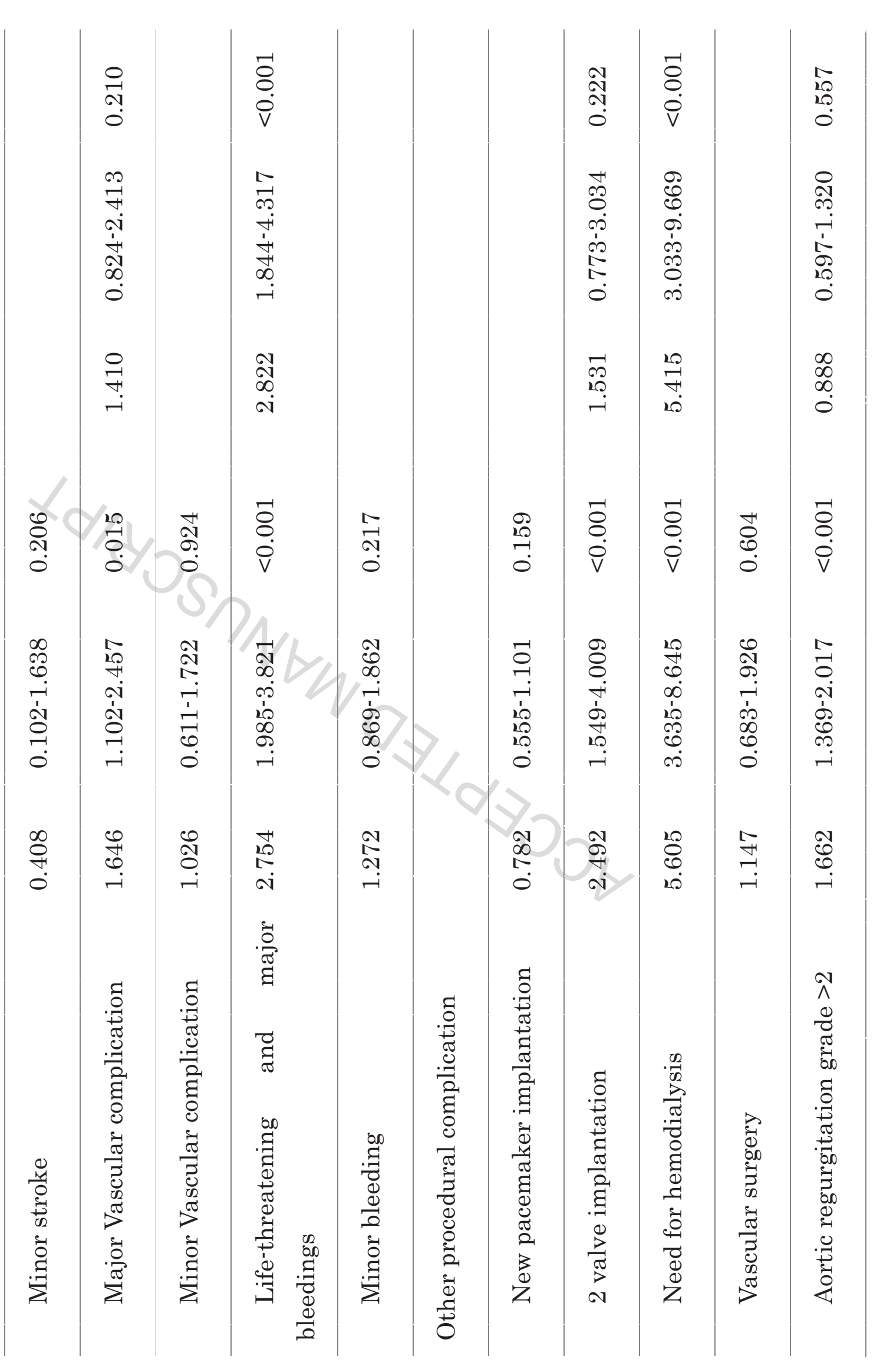




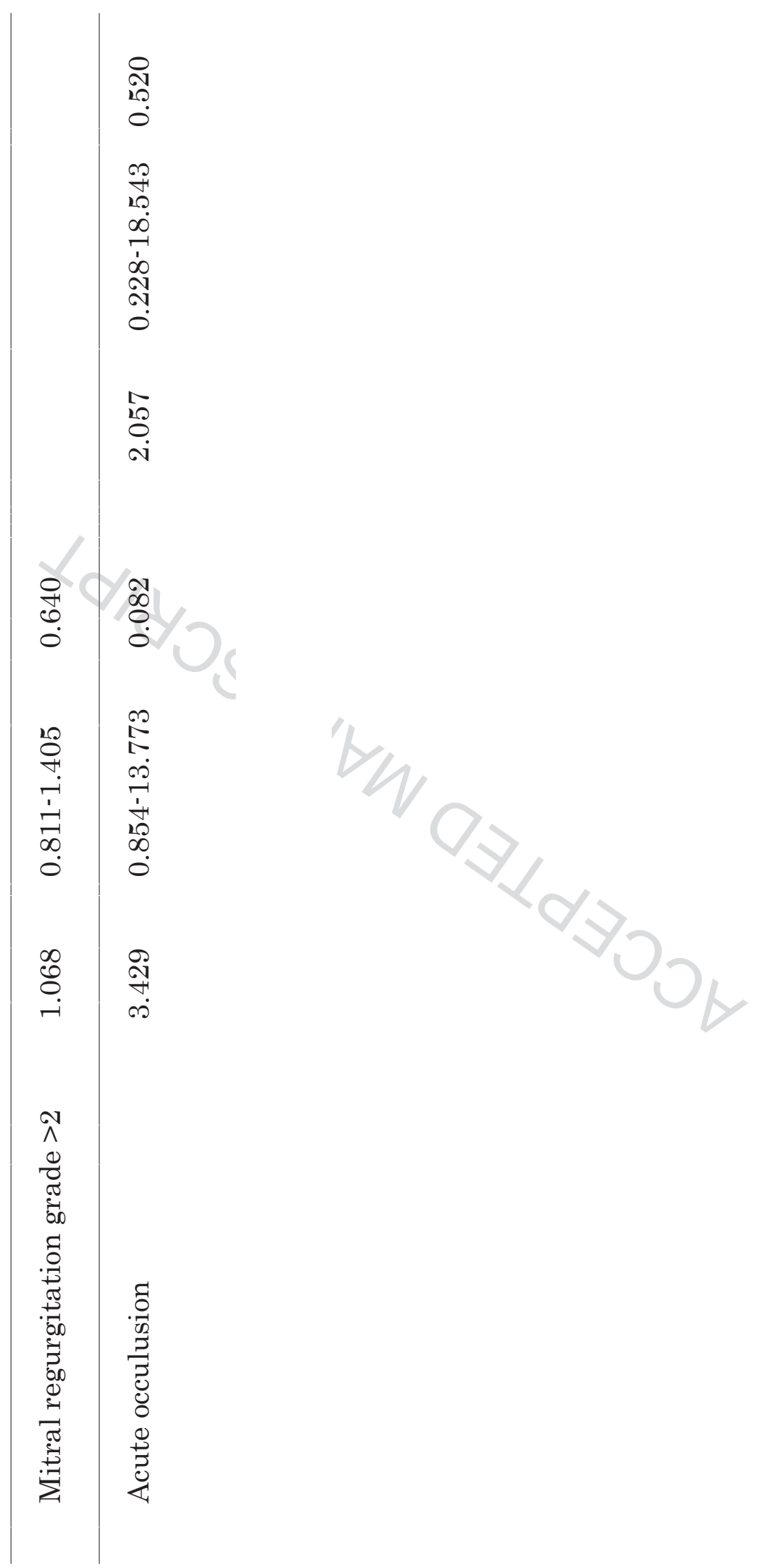

